\title{
Dealing with earthquakes: the practice of seismic engineering 'as if people mattered'
}

\author{
Edmund Booth ${ }^{1}$ iD
}

Received: 14 December 2017/ Accepted: 18 December 2017/Published online: 22 February 2018

(C) The Author(s) 2018. This article is an open access publication

\begin{abstract}
This paper sets out to explore the different ways in which communities deal with earthquakes. As is well known, the ability to recover from a damaging earthquake varies greatly across the world. The events of 2010 were of course a striking reminder of this, when the death toll from the Haït earthquake was at least 100,000; in the very different conditions of Chile, a much larger event the same year killed just 525 people. In a narrow sense, much of the difference can be explained in terms of the engineering properties of the physical infrastructure affected; the better it has been designed and constructed to withstand strong ground shaking, the greater the chance that the community affected has of recovering quickly. However, the central thesis of this paper is that the ability of a community to deal with earthquakes involves much more than just technical factors. Seismically resilient buildings and other infrastructure will only be in place when an earthquake strikes if there has been a willingness and ability to devote the necessary resources to building them. Moreover, taking prior steps to limit physical damage is only one part of the process for dealing with earthquakes; providing for immediate post-earthquake needs and for the longer term rebuilding of communities is also important. To pursue these issues further, and how they might affect engineers, I visited four widely differing regions of high seismicity. During this study tour, I examined the societal context in which seismic engineers operate and talked to many people involved in earthquake protection and response. The intention was to identify the ways in which the ability of communities to deal with earthquakes depend on societal factors such as economics, politics and more general cultural dimensions. Based on these investigations, I believe that seismic engineers can contribute more effectively to ensuring successful outcomes after an earthquake strikes if fully aware of these societal factors. We need to look beyond our narrow technical field of providing earthquake resistant facilities and widen our vision to consider the complex systems, both 'hard' and 'soft', in which those facilities will operate. E. F. Schumacher's famous book (Schumacher 1973) 'Small is beautiful' has the subtitle 'the study of
\end{abstract}

Edmund Booth

edmund@booth-seismic.co.uk

1 Edmund Booth Consulting Engineer, 2 Miswell Cottages, Icknield Way, Tring HP23 4JU, UK 
economics as if people mattered'. I believe that seismic engineering should be practised 'as if people mattered'.

Keywords Earthquakes · Resilience $\cdot$ Seismic standards $\cdot$ Professional education $\cdot$ Earthquake insurance $\cdot$ Cultural issues

\section{Introduction}

\subsection{Seismic engineering as if people mattered}

The ideas behind this paper first started to form when I was preparing the third edition of a basic textbook on earthquake engineering. My book (Booth 2014) was intended to set out the broad technical principles that a seismic engineer needed to be familiar with in order to be a successful designer of earthquake resistant building structures. The treatment was necessarily partial and personal, and inevitably contained at least some errors and important omissions. But even if that had not been the case, I realized that the tools of the trade of the earthquake engineer that the book tried to describe could never by themselves solve the problem of 'dealing with earthquakes'. The elegant and innovative solutions that the engineer devised might not be successfully implemented by the contractor, or they might not address the real performance concerns of their intended occupiers, or they might be unaffordable, or they might fail to address issues that had nothing to do with earthquakes, such as practicality for daily living or architectural delight or coping with other environmental influences such as wind, flood, temperature. It was a big subject involving a wide range of actors outside the structural engineering profession of my intended readers, but I wanted to help them widen their vision to encompass issues beyond their field. I was fortunate in having an editor who allowed me the time to write a new first chapter 'The nature of earthquake risk' which started the discussion of these issues. I was even luckier to be asked to present this Mallet-Milne lecture and to develop the ideas still further. Thus was born the idea for a longer treatment of 'seismic engineering as if people mattered', a sub-title poached from that of E. F. Schumacher's classic book on economics, 'Small is beautiful' (Schumacher 1973).

\section{2 'Earthquakes are different'}

Earthquakes are different from many of the other conditions that structural engineers encounter. There are technical issues to consider; unlike hurricanes, earthquakes shake both inside and outside of the building, affecting structure and services alike. They often trigger equally alarming and damaging events: landslides, fires, tsunamis. But I believe that there are two more fundamental issues that pose particular challenges for engineers in their dealings with the wider world. Firstly, return periods of events that cause significant damage to a region are usually long, sometimes extending to many generations. Coupled with this, earthquakes are much more 'unpredictable' than other environmental loads; it is possible to warn with confidence that a particular region is prone to strong earthquakes, but to predict when they will occur is currently impossible, and maybe always will be. Forecasts a few days into the future can be made for weather systems anywhere in the world, which are reliable enough to form the basis of effective action to protect society against wind storms, flooding and other hazardous weather conditions (Silver 2012). Volcanology has also advanced to a point where advance warning of eruptions is usually 
possible (McNutt 1996). The best that is currently available for the seismic hazard is to warn potentially affected regions at most a few tens of seconds before they are struck, and always after the causative fault has broken (Johnson et al. 2016).

It is true that in the last 40 years, enormous strides have been made at a technical level to deal with both these issues - that is, the long return periods and the unpredictability. However, the general public will probably find it very hard to understand the technical language that seismic engineers use to talk about these matters. And there is a problem of communication in the other direction, too; we engineers might find it difficult to understand the ways in which people living in earthquake country view the threat. For one thing, they may not give high priority to preparing for an event which might never affect them or their children. So there are real issues of communication here.

One reaction of seismic engineers to all of this is to stick with the complex technical matters of our subject, which we are good at, and let others worry about the wider issues, which we may not understand. Taking this stance, we allow others to set the standards and objectives to which we work. I think under many circumstances this stance is valid and often inevitable; it is probably one that I have unconsciously taken in most of my work as an earthquake engineer. But as a profession, we cannot then make the often-heard complaint that we are not given the status we are due, because we are effectively the servants of others higher up in the decision-making chain. And perhaps even more importantly, I believe that earthquake engineers have a unique contribution to make to the problem of 'dealing with earthquakes'; we certainly do not have all the answers (another fundamental assumption of this paper which I hope to justify in later sections), but we do have some crucial contributions. Examining the wider issues affecting the seismic resilience of societies and the implications that these issues have on our effectiveness as seismic engineers forms the main body of this paper. The intention is that an examination of the issues may enable us to be more effective-and influential—in driving the agenda of protecting society against the earthquake threat.

\subsection{What earthquakes share with other natural hazards}

Earthquakes certainly have their own very distinctive features, which have a profound influence on the best ways of dealing with them. However, they also share common features with other natural hazards, particularly rapid onset ones like windstorms, floods or volcanoes. One of these common features is that the resources that are devoted to recovering from a large-scale natural disaster often greatly exceed the mitigation efforts that preceded the disaster; this particularly applies in developing countries (Clarke and Dercon 2016). Another is that the response during the first few days after the disaster is often chaotic. There is the general issue of whether response should be 'top down' or 'bottom up', a topic which appears throughout this paper. Is a rapid, well controlled response from government preferable to a slower, possibly technically inferior, response controlled or at least influenced by local communities, which may be slow but better suited to local needs? Also, many countries are subject to extreme natural hazards of more than one kind, and the technical solutions that are good for one kind of hazard may not suit another; for example, heavy roofs are good for hurricanes but potentially lethal in earthquakes. This raises the point that seismic engineers need to be in dialogue with wind and other types of hazard engineers. Perhaps because earthquakes are so distinct, our seismic community sometimes neglects to do this. 
Finally, the ability of a local community to prepare for, and respond to, natural hazards is crucial to the way they deal with all of them; it is not just for earthquakes that people matter.

\subsection{The investigations carried out}

The general public in the UK is usually very interested in earthquakes (and volcanoes, which they often conflate with earthquakes) but generally they are not seriously concerned about the seismic threat to the UK. This is entirely rational; Roger Musson, a previous Mallet-Milne lecturer, estimates that in the last 400 years, earthquakes in the UK have killed only around 10-12 people (Musson 2003). The amount of damage that earthquakes have caused in the UK is trivial compared with that due to floods and windstorms, let alone that caused by human activities associated with, for example, transportation or war (Arup 1993). So to investigate further how society deals with earthquakes, I wanted to travel beyond the UK to places where they were of real concern, and I was very fortunate in obtaining generous travel grants from the Institution of Civil Engineers' Research and Innovation fund, Society for Earthquake and Civil Engineering Dynamics (SECED) and Earthquake Engineering Field Investigation Team (EEFIT) to visit the four regions discussed in Sect. 2. The methodology employed was rather unsystematic; I used my contacts in the four regions visited to gain interviews with professionals involved in seismic protection and response; most, but by no means all, were engineers. Altogether, 48 people were interviewed ("Appendix 1"). The interviews concentrated on the interviewees' personal experience of responding to earthquake issues, but were otherwise unstructured. In addition, 19 people with a professional interest in dealing with earthquakes were interviewed, either in person or by email ("Appendix 2"). Twelve were based in the UK, two in Germany and one each in California, Chile, Italy, Japan and Turkey. Confidential notes of all the interviews have been retained.

I make no apology for the unsystematic nature of these procedures, which would no doubt horrify most professional researchers in the fields of both engineering and the social sciences. The views expressed are necessarily very personal ones, and the haphazard procedures in some ways accord with the essential 'messiness' of my subject, discussed later.

\subsection{Layout of the paper}

Table 1 gives a contents list of the paper. Section 2 describes the study tour I undertook for this paper, and presents brief snapshots of what I discovered about how wider societal issues influence earthquake engineering in the four countries I visited. Section 3 looks at the training and professional organisation of engineers; it examines our status in society and our ability to communicate with people outside our profession, again in the context of our contribution to promoting seismic resilience. Section 4 examines the potential of the technical fixes we design as engineers to help society deal with earthquakes, as well as their limitations. I discuss the extent to which technical fixes need to be adapted for the characteristics of the societies they are intended for, and I conclude this section with some thoughts about how our engineering mindset affects our success as seismic engineering designers. Section 5 discusses seismic engineering standards. Section 6 moves away from engineering issues to look at the role of earthquake insurance in helping societies deal with earthquakes. Section 7 moves even further from seismic engineering to discuss social, 
Table 1 Contents of the paper

\begin{tabular}{|c|c|}
\hline 1 Introduction & 1.1 Seismic engineering as if people mattered \\
\hline & 1.2 'Earthquakes are different' \\
\hline & 1.3 What earthquakes share with other natural hazards \\
\hline & 1.4 The investigations carried out \\
\hline & 1.5 Layout of the paper \\
\hline 2 Study tour & 2.1 Overview \\
\hline & 2.2 Kathmandu, Nepal \\
\hline & 2.3 Northern California, USA \\
\hline & 2.4 Wellington and Christchurch, New Zealand \\
\hline & 2.5 Santiago de Chile \\
\hline 3 The education and professional organisation of & 3.1 The study and teaching of engineering \\
\hline & 3.2 The nature of the 'engineering mind' \\
\hline & $\begin{array}{l}\text { 3.3 Professional associations and the appeal of seismic } \\
\text { engineering }\end{array}$ \\
\hline & 3.4 Gender and inclusiveness issues \\
\hline & 3.5 The status of seismic engineers in society \\
\hline & 3.6 Engineers in dialogue with the wider community \\
\hline & $\begin{array}{l}\text { 3.7 The seismic engineering community as lobbyists: the } \\
\text { example of the CSSC }\end{array}$ \\
\hline 4 Technical fixes and the rational seismic & 4.1 Technical fixes for dealing with earthquakes \\
\hline & 4.2 Technical fixes for developing economies \\
\hline & 4.3 Technical fixes for disaster response \\
\hline 5 Seismic engineering standards & 5.1 The role and effectiveness of standards \\
\hline & 5.2 The scope of seismic construction standards \\
\hline & 5.3 Making standards \\
\hline & 5.4 Appropriate standards for low-income countries \\
\hline 6 Earthquake insurance and other financial & 6.1 The role of insurance in dealing with earthquakes \\
\hline & 6.2 Risk transfer \\
\hline & 6.3 Risk reduction \\
\hline & 6.4 Risk quantification \\
\hline $\begin{array}{l}7 \text { Social, political, economic and cultural } \\
\text { influences on seismic resilience }\end{array}$ & $\begin{array}{l}\text { 7.1 The Human Development Index and the impact of } \\
\text { earthquakes }\end{array}$ \\
\hline & 7.2 The definition and dimensions of resilience \\
\hline & 7.3 Cultural dimensions \\
\hline & 7.4 Political dimensions \\
\hline & $\begin{array}{l}\text { 7.5 The international dimension and the role of the } \\
\text { United Nations }\end{array}$ \\
\hline & 7.6 Economic dimensions \\
\hline & 7.7 Dimensions of religion and belief \\
\hline & 7.8 The press and other media \\
\hline 8 The case for Buddhist seismic engineering & \\
\hline 9 Final reflections: the true nature of engineers & \\
\hline Acknowledgements & \\
\hline
\end{tabular}


Table 1 continued

Appendices

Appendix 1: People interviewed on the study tours (Table 2)

Appendix 2: Other people interviewed or consulted by email

Appendix 3: Basis of calculations shown in Figs. 3 and 4

Appendix 4: The global targets of the United Nation's Sendai Framework (UNIDSR 2015)

References

political, economic and cultural influences on seismic resilience. Once again inspired by Schumacher's 'Small is beautiful', in Sect. 8 I ask the strange question: "Could there be such thing as Buddhist seismic engineering, and if so what would it look like?" I conclude by reflecting on the true nature of engineers and how it influences our contribution to 'dealing with earthquakes'.

\section{Study tour}

\subsection{Overview}

The four places visited are identified in Fig. 1 and Table 2; they are all in active seismic regions, and all have experienced damaging earthquakes in the last 7 years. However, in other ways, they are very different, with contrasting cultural, economic and political

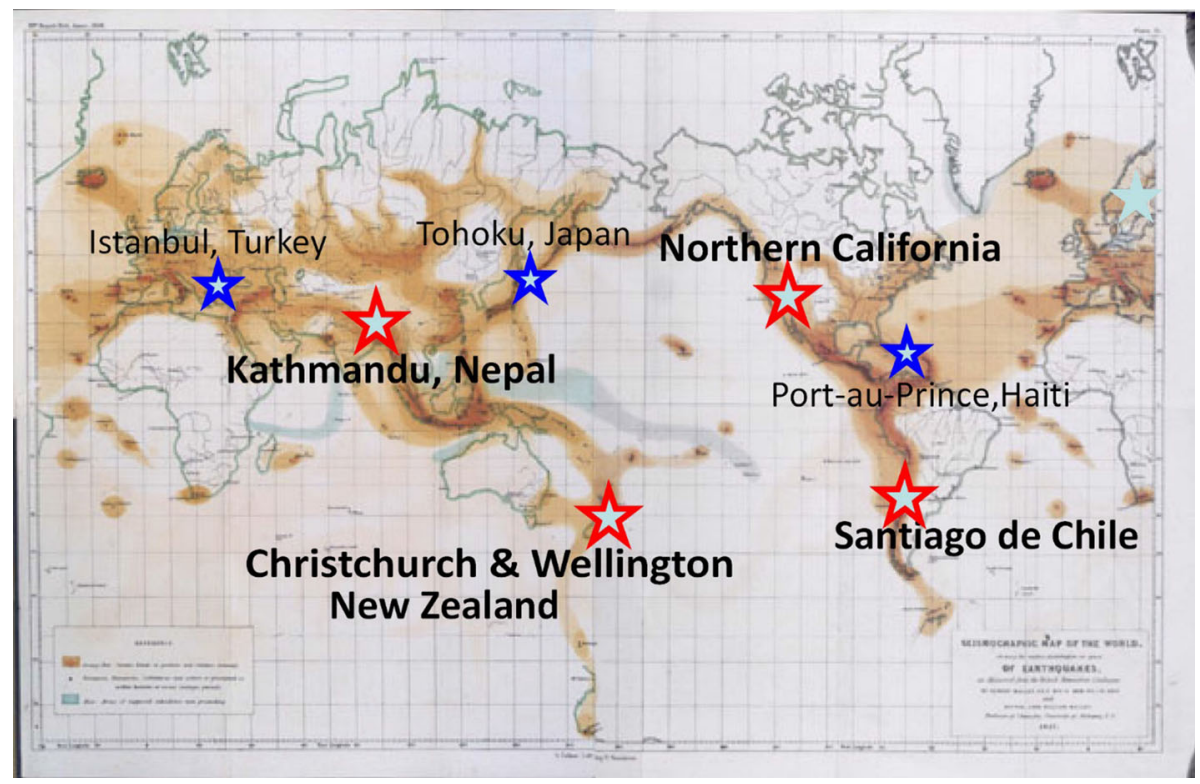

Fig. 1 Location of places visited in the study tour (red stars) and referred to in Table 3 (blue stars) shown on Robert Mallet's seismicity map of 1854-Fig. 18 in Musson (2013) 
Table 2 Places visited in the study tour

\begin{tabular}{|c|c|c|c|c|c|c|c|}
\hline \multirow[t]{3}{*}{ Region } & \multirow{3}{*}{$\begin{array}{l}\text { Date } \\
\text { visited }\end{array}$} & \multirow{3}{*}{$\begin{array}{l}\text { Recent significant } \\
\text { regional damaging } \\
\text { earthquakes }\end{array}$} & \multicolumn{3}{|c|}{ Associated effects ${ }^{a}$} & \multirow{3}{*}{$\begin{array}{l}\text { National per } \\
\text { cap. GDP } \\
\text { (US\$, 2015) }\end{array}$} & \multirow[t]{3}{*}{$\mathrm{HDI}^{\mathrm{b}}$} \\
\hline & & & \multirow[t]{2}{*}{ Deaths } & \multicolumn{2}{|c|}{$\begin{array}{l}\text { Cost of } \\
\text { damage }\end{array}$} & & \\
\hline & & & & $\begin{array}{l}\text { US\$ } \\
\text { billon }\end{array}$ & $\%$ GDP & & \\
\hline $\begin{array}{l}\text { Kathmandu, } \\
\text { Nepal }\end{array}$ & $\begin{array}{l}\text { Oct } \\
2015\end{array}$ & $\begin{array}{l}\text { Gorkha } \\
\left(\mathrm{M}_{\mathrm{w}}=7.8 \text { and } 7.3\right) \\
2015\end{array}$ & $\sim 9000$ & $7 ?$ & $\sim 35$ & 700 & Medium \\
\hline \multirow[t]{2}{*}{$\begin{array}{l}\text { N.California, } \\
\text { USA }\end{array}$} & \multirow[t]{2}{*}{$\begin{array}{l}\text { Aug } \\
2016\end{array}$} & $\begin{array}{l}\text { S. Napa Valley } \\
\left(\mathrm{M}_{\mathrm{w}}=6\right) 2014\end{array}$ & 1 & $1 ?$ & $<0.1$ & $64,000^{c}$ & $\begin{array}{l}\text { Very } \\
\text { high }\end{array}$ \\
\hline & & $\begin{array}{l}\text { Loma Prieta } \\
(\mathrm{M}=6.9) 1989\end{array}$ & 63 & 10 & 0.15 & & \\
\hline $\begin{array}{l}\text { Wellington and } \\
\text { Christchurch } \\
\text { New Zealand }\end{array}$ & $\begin{array}{l}\text { Sept } \\
2016\end{array}$ & $\begin{array}{l}\text { Canterbury quake } \\
\text { sequence } \\
\left(\mathrm{M}_{\mathrm{w}, \max }=7.1\right) \\
2010-2012\end{array}$ & 162 & 22 & 11 & 37,000 & $\begin{array}{l}\text { Very } \\
\text { high }\end{array}$ \\
\hline Santiago, Chile & $\begin{array}{l}\text { Jan } \\
2017\end{array}$ & $\begin{array}{l}\text { Maule }\left(M_{w}=8.8\right) \\
2010\end{array}$ & 525 & 30 & 12 & 15,000 & $\begin{array}{l}\text { Very } \\
\text { high }\end{array}$ \\
\hline
\end{tabular}

See Fig. 3 for the sources of information in this table

${ }^{\text {a }}$ The figures of cost of damage are indicative only, and some of the human casualty figures are highly uncertain

${ }^{\mathrm{b}}$ Human Development Index, which includes measures of education and health, as well as income

${ }^{c}$ GDP (gross domestic product) figures are given based on Californian GDP (i.e. excluding the rest of the USA)

characteristics. It can be seen that the damage and economic impact of the earthquakes was also contrasted sharply, in ways not obviously correlated to the earthquake magnitude.

Table 3 shows details of three further very destructive earthquakes in regions not visited for the study tour. The earthquakes all occurred since 1999 and ranged in magnitude from 7 to 9.1. Once again, there can be seen to be a sharp variation in their impact. This is a subject I will return to in Sect. 7.1

\subsection{Kathmandu, Nepal}

I visited Kathmandu in October 2015. Six months earlier, two large earthquakes had struck mid-western and central Nepal, causing nearly 9000 deaths and widespread damage in the mountainous areas north of the capital (EERI 2016). Kathmandu itself was spared the devastation which had been widely predicted for the next big earthquake (for example, GeoHazards International 2001), but it suffered many casualties and significant damage. However, when I arrived, I found to my surprise that the major issue of concern was actually not the earthquake, but a very severe shortage of fuel in the capital. (Concerns in the devastated mountain areas to the north would of course have been different, but I did not travel there). It turned out that although the earthquake was directly involved in the shortage, it had nothing to do with damage to petrochemical installations; actually, infrastructure in Kathmandu, including transportation links into the capital, was largely spared by the earthquake. The root cause was the bloody civil war which convulsed Nepal 
Table 3 Effects of three other recent damaging earthquakes

\begin{tabular}{|c|c|c|c|c|c|c|}
\hline \multirow[t]{3}{*}{ Region } & \multirow{3}{*}{$\begin{array}{l}\text { Recent significant regional } \\
\text { damaging earthquakes }\end{array}$} & \multicolumn{3}{|c|}{ Associated effects $^{\mathrm{a}}$} & \multirow{3}{*}{$\begin{array}{l}\text { National per cap. } \\
\text { GDP (US\$, 2015) }\end{array}$} & \multirow[t]{3}{*}{$\mathrm{HDI}^{\mathrm{b}}$} \\
\hline & & \multirow[t]{2}{*}{ Deaths } & \multicolumn{2}{|c|}{ Cost of damage } & & \\
\hline & & & $\begin{array}{l}\text { US\$ } \\
\text { billon }\end{array}$ & $\%$ GDP & & \\
\hline $\begin{array}{c}\text { Port-au- } \\
\text { Prince, } \\
\text { Haïti }\end{array}$ & $\begin{array}{l}\text { Port-au-Prince, }\left(\mathrm{M}_{\mathrm{w}}=7\right) \\
\quad 2010\end{array}$ & $100,000+$ & 6 & $>100$ & 700 & Low \\
\hline $\begin{array}{l}\text { Istanbul, } \\
\text { Turkey }\end{array}$ & Kocaeli $\left(\mathrm{M}_{\mathrm{w}}=7.6\right) 1999$ & $17,000+$ & $5 ?$ & $1 ?$ & 15,000 & High \\
\hline $\begin{array}{l}\text { Honshu, } \\
\text { Japan }\end{array}$ & Great East Japan $\left(\mathrm{M}_{\mathrm{w}}=9.1\right)$ & $\begin{array}{l}19,500- \\
\text { total } \\
800^{\mathrm{c}}\end{array}$ & 235 & 3.5 & 45,000 & $\begin{array}{l}\text { Very } \\
\text { high }\end{array}$ \\
\hline
\end{tabular}

See Fig. 3 for the sources of information in this table

${ }^{\mathrm{a}}$ The figures of cost of damage are indicative only, and some of the human casualty figures are highly uncertain

${ }^{\mathrm{b}}$ Human Development Index, which includes measures of education and health, as well as income

${ }^{\mathrm{c}}$ Most of the deaths from the Great East Japan earthquake were caused by the tsunami, with only about 800 due directly to ground shaking

in the 10 years up to 2009, causing at least 15,000 deaths (almost twice as many as in the Gorkha earthquakes) and leading to internal displacement of communities across the country. After the end of the war, and following the fall of the monarchy, there was the need for a new constitution. The new provincial boundaries that were drawn up for it followed an excellent civil engineering principle; they ran perpendicular to the contours, in order to maximise exploitation of the crucial resource for both irrigation and power of the snow melt from the Himalayas. That meant, of course, that people in the plains bordering India found themselves in the same political constituencies as the mountain people, who are ethnically distinct and have a very different way of life. Getting agreement to the new constitution was naturally difficult, given the experience of the civil war, and there was a large United Nations (UN) and other international presence in the country to try to facilitate it. However, it was the shock of the national disaster caused by the earthquake that finally persuaded members of the Nepalese Constitutional Assembly to sink their differences and the new constitution was ratified soon after.

The people of the plains were not happy; they had no constituency of their own, because of the way the boundaries had been drawn up, and hence felt that they lacked political power. But they have an important weapon; they live in the plains, and control the major land route from India into Nepal supplying the vast majority of the capital's fuel and other needs, and (with support from their ethnically similar neighbours in India), they closed the border point in protest for 5 months. The result was a severe shortage of fuel and some other commodities in the capital and other parts of Nepal.

This was for me a powerful example of the impact of an earthquake going far beyond its effect on buildings and infrastructure, and having consequences well outside the normal remit of earthquake engineers. It occurred in what is still one of the poorest countries in the world, despite high recent rates of economic growth. Geologically, Nepal is situated on the active boundary between the Indian and Eurasian plates. It is a boundary which regularly 
gives rise to great earthquakes, but the last Nepalese earthquake to exceed $\mathrm{M}=7$ before 2015 was in 1934. The civil war, now resolved, had led to a very large UN presence which still continues and there are many international aid agencies working in the country. The Kathmandu valley is home to 2.5 million people (more, by some estimates), which is $8 \%$ of Nepal's population (Wikipedia 2017a). It represents by far the largest conurbation in the country and the population is growing at $4 \%$ a year. However, most of the population live in rural areas, and agriculture accounts for three quarters of the workforce (Wikipedia 2017b). A significant proportion of those born in Nepal work overseas, including many in the Gulf region, and I was told that foreign remittances are an important part of the economy.

These data have many implications for the way Nepal deals with earthquakes. The geological setting gives rise to a significant seismic threat, but the last two large events in the country have been separated by three generations, and many other issues affect the daily life of most citizens. 'In rural areas, life was pretty miserable before the earthquake, and so the current misery post-earthquake hasn't changed things a lot', one of my Nepalese interviewees told me. Another interviewee pointed out that inhabitants in rural areas of the Himalayas are by necessity resilient, because there are constant environmental threats; they are in many ways much better equipped to deal with the consequences of earthquakes that the inhabitants of, say, San Francisco, not least because they have practically no reliance on external services like power, sanitation and public infrastructure. Nepal also has a longstanding experience of accepting external aid.

The rural setting of the worst affected region was associated with many of these observations on the consequences of the 2015 earthquake, but it also has implications for the way the community might prepare for the next big earthquake. Being an hour's steep walk from the nearest road effectively rules out cement-based solutions to building earthquake resistant houses; other more appropriate solutions do exist, but introducing them from outside poses formidable problems (Borchers 2017). One is that the attraction of the cash economy in the Kathmandu Valley, and places farther afield like the Gulf, means that there is a haemorrhage of skilled builders. Rural masons with traditional skills are understandably attracted to the possibility of sending home the proceeds of a (relatively) high salary from a building site in Qatar to support their struggling family in Nepal.

The setting in which professionals work also has implications for how earthquake resistance is achieved. There is a small but significant body of structural engineers in Nepal, many at least partly trained in centres of excellence overseas. The national member of the International Association of Earthquake Engineering (IAEE) is the National Society for Earthquake Technology, Nepal (NSET). Founded in 1993, and directed since then by Amod Dixit, it is widely and internationally admired for its work in fostering community efforts, especially in rural areas, to improve earthquake resilience; the mission statement on its website (http://www.nset.org.np) states its aims include "upgrading disaster awareness among school-children, house-wives, and commoner people and promoting capacity building of construction activists at grass-root level". Although its engineers represent some of the best technological expertise in the country, NSET's prime function is not as a learned association for exchanging knowledge, but as an agency to implement solutions to the seismic problem. In this, it is very different from a membership organisation like SECED, and Nepal does not have the sort of lively special interest group for earthquake engineers that is such a feature of California or New Zealand-and even the 'very low seismicity' United Kingdom. 
The needs of a place like Nepal for earthquake standards are discussed further in Sect. 5.4; it is clear that they are inevitably very different from those of a place like Christchurch New Zealand or San Francisco.

\subsection{Northern California, USA}

Northern California hasn't suffered a major earthquake since the Loma Prieta event of 1989, a generation ago. However, the San Francisco earthquake of 1906 is an event that many people worldwide know something about, in a way that does not apply to the 1934 Kathmandu earthquake, and the potential effects of a repeat of the 1906 event have been widely studied. California's economy is possibly the most technically sophisticated on earth and is one of the richest; its seismic codes are internationally leading, some even claiming that they surpass Eurocode 8 (CEN 2004), and they are well enforced. It has an active seismic engineering community of professionals and designers who share knowledge in a variety of highly effective ways. Northern California hosts two of the leading centres of earthquake engineering research, and is home to two organisations, Earthquake Engineering Research Institute (EERI) and Applied Technology Council (ATC), which have been crucially influential in the international development of earthquake engineering. These characteristics are quite distinct from those of Nepal, and the other places on the study tour, and it is not surprising that the way California deals with earthquakes is equally distinct.

When I visited Northern California, it appeared that preparing for a repeat of the 1906 earthquake was not high on the list of concerns of its citizens. A much bigger issue was the drought affecting the farms of the Central Valley, agriculture being a major part of the local economy. Everyone may know the joke about California 'having its faults', but seismic issues have to fight, often unsuccessfully, for the attention of the state legislature and of local jurisdictions. Top Californian seismic engineers do not appear to have the rock star status that might be expected; on the contrary, they seem to be viewed by most of their clients as mere facilitators of seismic regulations, hired to ensure that compliance has no significant economic implications.

\subsection{Wellington and Christchurch, New Zealand}

Earthquakes may have passed from the top of the agenda in Kathmandu and Northern California, but this certainly was not the case in New Zealand when I visited in the autumn of 2016, particularly in Christchurch. Nearly 5 years after the last destructive aftershock of the 2010-2011 'Canterbury earthquake sequence', as it is known by the seismologists, the Central Business District of Christchurch had reopened. However, there were still highly visible signs of what had happened, and reconstruction and seismic protection continued to be of great public interest and debate. Later that year, the $\mathrm{M}_{\mathrm{w}}=7.8$ Kaikoura earthquake blocked the main road between the port of Picton and Christchurch that I had travelled down a couple of months before.

New Zealand's population of under 5 million (Wikipedia 2017c) is about a quarter that of Chile, a sixth that of Nepal and an eighth that of California. Australia, its nearest large neighbouring country, is separated by $2,000 \mathrm{~km}$ of ocean. It is a developed country with a successful and quite diverse economy, where engineers are well trained, well respected and form a rather close community; many were educated at the University of Canterbury and the national seismic engineering society, the New Zealand Society for Earthquake 
Engineering (NZSEE), is lively and produces an influential quarterly bulletin of international quality. One of my informants told me:

Professional engineers are highly considered in New Zealand, and the public perception of 'corruption' in the profession is low - much lower than in Italy, for example.

The national seismic regulations are well enforced, and are widely respected internationally. Remarkably, given its size, New Zealand has had a profound influence on the conduct of seismic engineering worldwide; notable examples are the concept of capacity design, first formulated at the University of Canterbury, and the modern development of base isolation, which was pioneered in New Zealand.

The Canterbury earthquake sequence thus struck a rather close-knit and relatively small but highly developed society, which was well aware of the threat of earthquakes and how to deal with them. The earthquakes were particularly traumatic for two reasons. Firstly, they gave rise to ground motions significantly greater than those provided for in the code. Secondly, the aftershock sequence continued for many months after the main shock; it was the first major aftershock which caused most damage, and during 2011 there were altogether four aftershocks with an intensity MMI $\geq 8$ (destructive) (Wikipedia 2017d), all of which caused structural damage. This long drawn-out threat caused profound reactions; Sir Robert Parker, mayor of Christchurch at the time of the earthquakes, told me:

Many people haven't been the same since the earthquake sequence, and that includes some of my relatives. This was a reaction to so many significant damaging earthquakes over a 2 or 3 year period. One didn't sleep without half an ear for the next event, and got very good at judging the magnitude. We slept with makeshift arrangements - e.g. under the table. This showed our strength - the New Zealand grit, which makes us great rugby players. Of course, some people left the city to escape. ${ }^{1}$

The way to cope with the ongoing threat and proceed with reconstruction gave rise to fierce debate; for example, the Canterbury Earthquake Reconstruction Authority initially proposed that McLean's mansion, a magnificent timber building dating from 1899, should be demolished since it posed a hazard. This gave rise to strong protests from the community, and the building was saved (Wikipedia 2017e). While acknowledging that mistakes were made during Christchurch's reconstruction, Bob Parker's evaluation was that in many ways things went very well-it was 'a huge success'. I accept that evaluation, and find much to admire and learn from what happened. ${ }^{2}$ Interestingly, it seemed to be generally accepted that the much fiercer intensity of shaking than that provided for in the building standard was not a reason to blame the seismologists. The ground motions significantly exceeded previous estimates for the 2500 year return period event (McVerry et al. 2012), but could not have been reasonably foreseen, and the event taught new lessons to seismologists worldwide. The situation after the L'Aquila earthquake of 2009 in Italy and the Great East Japan earthquake of 2011 was very different, where criticism of seismologists was fierce (Wikipedia Wikipedia 2017f, g).

\footnotetext{
1 This is a paraphrase of Sir Robert Parker's actual words.

${ }^{2}$ For a detailed assessment of the governance of the Christchurch reconstruction process, see Johnson and Mamula-Seadon (2014).
} 


\subsection{Santiago de Chile}

Chile is the most seismically active of the four places visited on the study tour; great earthquakes occur along its Pacific coastline at least once every generation, and the coastal population generally knows both that a tsunami is likely to follow a strong earthquake and what is the appropriate action to take. Stephen Platt (2012) notes that earthquakes and tsunamis razed the town of Concepción in 1570, 1657, 1687, 1730, 1751, 1822, 1835, 1868, 1877, 1906, 1918, 1922, 1937 and 1960. He reports a conversation he had in a coastal village devastated by the tsunami following the 2010 Maule earthquake. He was talking to Juan Rivera Carmiolo, a fisherman who was the president of the local residents' association:

Juan described how most people were asleep when the earthquake struck, causing little damage. "But people knew what to expect and they immediately decamped for the hills behind the village. Many were not dressed properly and it was a cold night. There was a bright moon so we had light to climb by. Between 5-6 am we heard the wave. The second wave was $8-9$ metres high and took everything. We had heard our parents recount the events of 1960 but the tsunami was so strong I never want to experience anything like that again. Those near the shore lost everything. The village was completely inundated and the roads were full of debris. There was so much destruction. The school was completely destroyed, there were ships in the street and all the equipment - the compressors and outboard motors were lost. The bridge was down and lorries bringing supplies had to go the long way round. Many people couldn't cope. Some remained strong and had to work for the rest."

The short interval between large earthquakes affects not only the general public but also professionals; Ramon Verdugo, a leading Chilean geotechnical engineer in design practice told me: "I am $100 \%$ sure that all the projects I am responsible for will suffer a big earthquake; this is what forces me to do my best all the time, looking carefully at all details to avoid potential problems and to rely on the final result. This is very stressful because always the amount of uncertainties are significant".

The Chilean seismic code is widely considered as effective, and well enforced. Significantly, Chilean structural engineers enjoy a high status. They can expect a good salary; several of my Chilean interviews told me that for those working for a contractor, it is greater than that of lawyers. Clients and architects appear to be prepared to work with the solutions that engineers suggest for providing seismic resistance, even if it involves putting large shear walls through the middle of lettable spaces. "If the structural engineer says something is necessary to provide earthquake protection, the rest of the design team and the client are prepared to accept it is necessary to take the nasty medicine" one of my interviewees told me.

Chilean society appears to have produced more than just good technical solutions to providing earthquake resistance; the political and organisational response to reconstruction after an earthquake also works well. In commenting on the response to the Maule earthquake of 2011, Stephen Platt and Emily So (2017) state: “Our impression, from talking to people in the various coastal settlements we visited, was that the need to balance speed and deliberation had been managed with some skill". In other words, the speed provided by a strong central government response still allowed the deliberation and consultation with local communities that led to rebuilding in a way that satisfied local needs. This is a topic-that of 'top-down' versus 'bottom-up' response-that I will return to in Sect. 7.3. 
A rather interesting and instructive anecdote illustrating Chilean attitudes to achieving earthquake resilience was sent me by Vitor Silva of the organisation Global Earthquake Model (GEM). Vitor comes from Lisbon, which suffered a devastating earthquake and tsunami in 1755, but has had little seismic damage since then.

Let me give you an example of my experience with taxi drivers in Santiago and Lisbon. I am always curious to know more about the cities where I am, and I think taxi drivers are great tourist guides. In Santiago I explained [that I was attending an [earthquake engineering] conference there, and right away the taxi drivers started telling me about why buildings in Chile were designed to withstand earthquakes, what I should do in case something should happen, how earthquake insurance worked in the country. One of the drivers even taught me how to measure the distance of earthquakes based on the duration of the event. In a similar trip in Lisbon, when I told the taxi driver that I was an earthquake engineer, he told me that since the earthquake already happened, it should not happen again in Lisbon, and furthermore, he lived in a brick house over 100 years old, and if it survived for 100 years, it would survive another 100 for sure. Another driver also told me that the old buildings were much better than the new ones, because in the old days, people knew how to build, but not today. So probably the same social classes between Chile and Portugal, but very divergent positions.

\section{The education and professional organisation of engineers}

\subsection{The study and teaching of engineering}

David Blockley (2012) defines the purpose of engineering and technology (words which he treats as synonyms) as being to produce "useful physical tools"; these tools (I prefer to say 'artefacts') must be not only useful but also have "other qualities such as being safe, affordable, and sustainable". He contrasts this with the purpose of science-"creating theory and knowledge" - and the purpose of mathematics- "clear, unambiguous and precise reasoning". Clearly, modern engineers need a lot of knowledge and theory, and being able to reason precisely helps too, so much of our training is connected to these qualities. However, our end product must, essentially, be useful too, and this is perhaps what sets us apart from others who work on our side of the great humanities/science divide.

Engineers producing 'useful physical artefacts' have been around since the dawn of human history, but we don't know how engineers working for the Pharaohs were educated, or exactly how the ancient Greeks worked out how to construct buildings, at least some of which have proved so remarkably resistant to earthquakes (Makris 2015). The academic study of engineering at my alma mater Cambridge University can be traced to the establishment in 1782 of the Jacksonian professorship of 'Natural Experimental Philosophy'. This was founded for 'the promotion of real and useful knowledge' which 'cannot be done by mere reading but by shewing and doing something in the way of experiment' (Ahmed 2017). Remarkably, this was at a time when the university was still principally intended for those intending to enter the Church. The creation of a department of engineering (still called 'mechanical sciences' when I was there in the sixties) came rather later, being just 150 years old. My training in engineering at undergraduate level lasted just 2 years, and that was the extent of my full-time training in the subject. Now, in most cases, UK engineers must have completed a Masters in Engineering lasting 4 years, and then be 
engaged in practice for a few years more before achieving chartered (fully qualified) status. In continental Europe, longer periods of training are needed to become professionally qualified and in Chile, professional engineers need to have studied for 6 years, but the requirement for the practical experience-the apprentice stage-is absent.

In order to acquire the theory and knowledge needed to understand and help design the complex systems represented by today's 'useful physical artefacts' certainly requires many years of study. This is true whether we are involved at a broad level, ensuring the elements of the system work well together or at a detailed level designing the complex elements themselves. (Achieving mastery at both system and detailed level is probably beyond the reach of most of us-we are either 'foxes' or 'hedgehogs', to use the language of Isaiah Berlin's (1953) famous essay). In the past, which in some respects posed less complex problems, this was usually achieved by being apprenticed to a senior engineer, and most of my development as an engineer took this form (and it still does). Arguably, training students in the rigour and discipline needed for successful engineering, is just as important as the teaching of specific techniques. In any case, many of the latter that I was taught at university are now obsolete, a trend that I suspect will continue at increasing speed. So moulding young brains to become 'engineer-like' is a crucial task of universities, and promoting 'Engineering Habits of Mind' is a key recommendation of a recent report by the Royal Academy of Engineering (Lucas et al. 2014). A leading Chilean engineer, who had set up a successful design practice after some years as an academic, told me "The intensive maths of the first undergraduate year [of Chilean engineering courses] is seen as a way to 'deform the brain' and create students with the right way of thinking".

\subsection{The nature of the 'engineering mind'}

Does this rigorous training, this desire to shape young brains, carry dangers? Does it make us too much in love with the technicalities of our subject, able to understand only the 'hard components' of the systems we work with, and not the 'soft components', such as politics, communities, even people, which involve inherently messy and ungovernable features? Does it mean that engineering courses mainly attract students with nerdish tendencies, and then reinforce those tendencies still further? In short, are we as engineers somewhat towards the abnormal end of the autistic spectrum, unable to relate to the people for whom the useful artefacts we create are intended?

This is of course a distorted caricature; if my picture of the typical engineer were generally true, then most engineering projects would fail, and the useful artefacts would not appear, for two reasons. Firstly, we work towards our ends in teams, and if we could not cooperate fruitfully and harmoniously with each other, we would not be successful. The director of an international engineering firm once told me "All technical problems can eventually be solved; it's the personal issues that are the most intractable". The second reason is that if we work towards ends that satisfy only ourselves and not the end users for whom our artefacts are intended, then eventually we will find the demand for our services disappears.

There is of course an essential role for brilliant nerds who are impossible to work with, because they are often the ones who propel us along the new path which makes progress possible. And there is nothing wrong with being in love with the fascinating technicalities of our subject; this is what fires our enthusiasm for excellence, and makes us willing to give up our spare time reading possibly tedious papers in engineering journals. Moreover, for many of us, what makes our profession so attractive is the range of different people, cultures and places it brings us into contact with, as well as the engineering challenges. The 
clear evidence of organisations like Engineers Without Borders or Register of Engineers for Disaster Relief (RedR) is that within the profession there is a strong streak of altruism and a desire to serve humanity. I believe that we have abundant personal skills to draw on from within our community, which makes it possible to practise seismic engineering as if people mattered. What I, and perhaps others, tend to do is that I compartmentalise my life, and find it difficult to allow my personal skills to influence my technical decisions. It is so obvious to me that an extra 5\% of effort should be spent in 'building back better' in a region that has just suffered a devastating earthquake; that is the conclusion my logical engineering training has led me to. But "'build back better is just an [unhonoured] slogan", one of the building officials in Kathmandu that I spoke to told me, 5 months after the worst earthquakes in three generations had struck the region. To have any chance of influencing attitudes like that, I would have to try and understand them first. That may not be easy for us to do.

\subsection{Professional associations and the appeal of seismic engineering}

A notable feature of civil and structural engineers in the UK is our enthusiasm to meet, discuss, debate and share knowledge. Perhaps this is because we are more willing to share our knowledge with others because it is less likely to result in creating consumer products which could make us billionaires, or perhaps it dates back to 1771 when Smeaton and his mates first met in a London coffee house to talk shop (Wikipedia 2017h)—a meeting which led directly to the foundation of the Institution of Civil Engineers. It certainly gives the lie to the notion that all engineers are unsociable nerds who find it difficult to relate to other people.

The seismic engineering community is particularly good at forming special interest groups. SECED is a case in point, but the willingness of groups from all over the world to host European and international conferences on earthquake engineering demonstrates that this enthusiasm is widespread. Another prime example has been GEM, whose activities are discussed in Sect. 6.4. GEM has been highly successful in mobilising support and cooperation for achieving its goal of producing a global map of seismic hazard and risk. At the time of writing, no other special interest group has been anything like as successful in producing global hazard and risk maps.

Seismic engineering holds a particular appeal for a number of reasons.

- The discipline has developed enormously since I first became involved more than 30 years ago, but there are still formidable technical challenges to solve, perhaps to a greater extent than is the case for, say, wind engineering.

- The drama and newsworthiness of damaging earthquakes ensures that the subject is often at the forefront of public attention.

- Field missions provide the opportunity to study at first hand in a very practical way how the discipline is progressing.

- Earthquakes cause widespread suffering, and seismic engineers are proud to be able to contribute to its alleviation.

A strong national earthquake engineering group should contribute greatly to the ability of the country to deal with earthquakes by providing a pool of experts who can provide and develop seismic resistant construction suited to that country's needs. It does depend on the social, economic and educational conditions that can provide the pool of suitably trained engineers to form the group. These conditions are clearly met in California, New Zealand, Chile and of course elsewhere. In Nepal, the conditions (and needs) are very different. The 
most important association of Nepalese seismic engineers, namely NSET, takes a very different form from, say, SECED; it is not a membership organisation in the same way and sees its main role as passing on appropriate earthquake resistant technologies to local communities, and those in the building trades who work there.

\subsection{Gender and inclusiveness issues}

In Sect. 3.2, I suggested that seismic engineers are often immersed in the fascination of technical issues and may find it hard to place their work into a wider context. Does the fact that ours is a male-dominated profession have any bearing on that? The fact that it is maledominated is hardly in doubt. SECED was founded almost half a century ago, but the current chair, Tiziana Rossetto, is the first woman to hold that post. There are currently three female members of the SECED committee (three more than when I was chair in 1991) but in a committee of 21 , that is still quite a small percentage. It is not just a British characteristic; at a recent meeting in Europe that I attended to discuss changes to Eurocode 8 (CEN 2004), there was only one woman among the two dozen technical delegates gathered from all over Europe. By contrast, two of the three administrators were female.

There is no direct evidence of which I am aware to show that increasing the percentage of women in teams of engineers leads to a change in outcome. Even in other fields such as the percentage of female members of company boards, it appears the evidence is rather mixed (Rayasam 2013). Opinions on the subject differ; articles in the New Civil Engineer magazine on gender and diversity issues attracted a number of outraged responses (from men) suggesting that this was a distraction (see NCE 2015), and that all that mattered for the effectiveness of an engineering team was the technical excellence of its members, not their gender, sexual orientation or racial origin. My logically trained engineering brain suggests to me that decisions about what is best for society as a whole can emerge more effectively from teams whose make-up bears some relation to the population they are trying to serve. I suspect that women are generally better at relating to the 'soft components' of engineering problems, referred to in Sect. 3.2, and maybe also be better at communicating with the general population, the subject of the next section. Of course I recognise that there is a large and overlapping spread of these skills among engineers of all types and backgrounds.

\subsection{The status of seismic engineers in society}

It was striking how the status of seismic engineers appeared to vary greatly between the countries I visited, in a way that was not obviously correlated to seismicity or economic development. As discussed in Sect. 2.5, the status of Chilean engineers appears to be unusually high; they can expect a high salary. In Chile, it seems that not only other construction professionals, but also the general public, are willing to accept as necessary and important the solutions they specify for seismic resistance. In California, this is reported not to be the case; for standard commercial and residential work, seismic engineers are expected to provide the lowest cost solution, which does not interfere with the client's and the architect's ideas, and it seems that things are much the same in the very different setting of Nepal. Of course, the regard for Californian expertise within the international seismic engineering community is very high, but esteem from one's international peers is different from the general public's opinion.

Within the much smaller population of New Zealand, structural engineers appear to be accepted as important contributors to the communal effort of providing seismic safety. It is 
also a community that has produced some of the most notable advances in earthquake engineering of the last 30 years.

As for Japan, a distinguished Japanese engineering professor reports: "I have to say that the status of engineers in Japan is very low. Engineering judgements are almost not allowed at all in order to keep the uniform conformity check throughout Japan". Technical fixes providing earthquake resistance are however adopted with some enthusiasm; for example, the take up of seismic isolation has been more substantial in Japan than anywhere else. The substantial research and development (R\&D) budgets of the major Japanese construction firms plays a role here.

Polat Gulkan, a leading seismic engineer in another highly seismic country, Turkey, reported:

Engineers in Turkey don't command the degree of societal respect that you say their peers in Chile do. That also translates to the low-to-modest pay scales they are handed. I think the excess number of engineers has to do with that: when supply exceeds demand the laws of economics say the price of a commodity or service dips. The ruthless competition among structural design offices means that they are often forced to bill their clients at rates lower than the legal minimum levels. The earnings of an engineer and a lawyer at the same level of professional competence are slanted in favor of the latter ......... A typical structural engineer in Turkey doesn't have the luxury of ordering robust shear walls in most residences because contractors and owners abhor cost rises.

This low opinion of structural engineers in Turkey is confirmed by a fascinating study of reconstruction after the Izmit earthquakes in Turkey of 1999 by Rebekah Green (2008). She found that Istanbul residents faced with rebuilding their homes were unlikely to seek professional engineering advice. This was not just because engineers were perceived as expensive, indeed extortionate, but also because they were seen as having nothing useful to offer. Green reports that as a result, the reconstructed buildings had many of the same faults that brought down the buildings they replaced.

This example raises the more general issue of public trust for experts, not just in Turkey but worldwide. Almost everyone can now become an expert with the aid of the Internet, even if that expertise may be partly based on 'alternative' facts. Public mistrust of engineers may also be tempered by a widespread need to find people to blame. Polat Gulkan reported: "The media mercilessly targets structural designers in Turkey with all the ills of the building design and delivery chain in the wake of terrible building performance during earthquakes"; that may well help explain the findings of Rebekah Green's research, quoted above.

The degree of trust in experts is highly dependent on culture. The IFRC's (2014) World Disasters Report cites a recent example of the interaction between local beliefs and expert advice. In Java in 2010, expert warnings of an imminent volcanic eruption were ignored by local people; they refused to evacuate not just because they wanted to protect their livestock, but crucially because they had not been instructed to leave by the juru kunci. This was the gatekeeper of the volcano who, the local community believed, was in touch with the spirits controlling the volcano; they were well aware of the hazard but chose to rely on their local traditions rather than outside expertise. Sadly, the juru kunci and 300 others were killed when the volcano did erupt. This colourful example may be difficult to relate to the situations we usually find ourselves in, but cultural influences on the attitude towards experts is much more widespread than that; the difference in status of seismic engineers between the four countries I visited, I suspect, has its roots in cultural difference. 
There is a wider aspect to this. Political events of 2016-the surprise results of the recent European Union referendum in the UK and the presidential elections in the USAsuggest there may be an increasing and general trend towards public mistrust of experts. The Nobel prize winning psychologist Daniel Kahneman (2011), in his book 'Thinking fast, thinking slow' has a section entitled 'The public and the experts', in which he discusses the extent to which experts should and do account for public perceptions of risk that differ from their own. This is highly relevant to our work; if the willingness of society to accept solutions that we propose cannot be taken for granted, then our ability to contribute to the task of dealing with earthquakes is affected, and our methods of working need to change.

It is important that we do not become over-defensive as a reaction to public questioning or even hostility. We can perhaps accept that public mistrust of economists had at least some justification, following the failure of almost all of economists to warn of the impending global financial crisis of 2008, and the fact that the majority of them warned of immediate dire economic consequences, if Britain voted to leave the European Union. We must not assume that people outside our discipline challenge us because they are too stupid or ignorant to understand what we are doing; we need the humility to admit not only that we might sometimes be wrong, but also that non-engineers may have better ideas than we do. In a study of rebuilding after the Kashmir earthquake of 2005, Randolph Langenbach (2009), in his book 'Don't tear it down', found that certain forms of traditional construction, which comprised a combination of timber with unreinforced masonry bonded by weak mortar, had generally survived the earthquake very well, and overall very much better than ones reinforced with modern materials. However, engineers regarded these traditional buildings, at least initially, as prime candidates for immediate demolition, even where undamaged, and certainly not as models for the rebuilding programme. He attributes this to the fact that traditional construction is much harder to analyse with the sort of tools used for concrete or steel structures, and to a more general prejudice and lack of knowledge by professional engineers about rural building forms. These attitudes may well result from the way seismic engineers are often trained; in the teaching I have done, I always include examples of the successes as well as failures of traditional (as well as engineered) construction in earthquakes.

The status and perceived trustworthiness of engineers have important implications for how we communicate with those outside our discipline (Sect. 3.6) and how decisions are reached on the performance goals that are set in engineering standards (Sect. 5).

\subsection{Engineers in dialogue with the wider community}

As engineers, we are all aware of the fact that most of our non-technical friends have no conception of what we actually do, and that the media regularly misunderstands or ignores our contributions. On the one hand, we are lumped into the same category as technicians; "Network Rail engineers have been working through the night to protect the most damaged section of sea wall in the coastal town of Dawlish" read a UK headline in 2014, and while no doubt at least one chartered civil engineer formed part of the all-night team described, that's not what was conjured up in most people's minds. Interestingly, the concept of an 'engineer' coming to repair a damaged radiator (common parlance in the UK) is reported to be completely alien in Chile. On the other hand, our professional work is not understood; it is widely believed (at least in the UK) that though structural engineers might have something to do with the foundations of buildings, architects do most of the rest. The misconception that the distinguished British architect Norman Foster, rather than the great 
French bridge engineer Michel Virlogeux, deserves the principal credit for the Millau Viaduct in the south of France is almost universally believed in the UK (but no doubt not in France!).

Seismic engineers are just as prone to be at the receiving end of these misunderstandings, although the handle 'earthquake' does help rouse interest to some extent. We sigh, and get on with our work because we enjoy it and think it useful. But if there is any validity in my thesis - that it is important to connect with the communities we serve-then that is not good enough. We have to make the effort to get out of our comfort zone, explain what we do to our non-technical friends, our communities and the media. A few of us are spectacularly bad at this, a few wonderfully good, but most of us come somewhere in between, and need to improve through practice. The initial education we received to 'deform our minds' into the engineer mould may actually make communications harder, and encouraging engineering students to have a broad range of interests is widely, and rightly, seen as important, though not always easy to implement. My experience of helping with third year undergraduate design projects at Oxford University suggests such projects are a great way of doing this; as well as solving difficult engineering challenges, the students had to work in a team, present their results clearly to others and establish what the purpose and performance characteristics should be of the 'artefacts' they were designing. Designing a footbridge across a beautiful stretch of the River Thames, and planning the infrastructure of a refugee camp in a remote part of Africa-the two projects I was associated with-challenged the students in all these ways. Combining the study of engineering with economics and management is another way towards achieving this; in my final year at university, I switched to economics and found myself defending essays to my tutor, sitting next to a future governor of the Bank of England. Of course, it would also help communications if this did not only apply to technical students, so that arts students, too, were encouraged to have a 'broad range of interests' including technical and engineering ones.

The way in which engineers communicate with the press and other media is clearly important to the way their work is perceived by the general public. The following advice was given to me by Bob Parker, the former mayor of Christchurch. He started life in broadcasting, and so was acutely aware of how the press reported handling by engineers, as well as politicians, of the crisis that was unfolding in Christchurch after the earthquakes. His advice is striking:

Important professional groups need to develop a clear line and a strategy, and have it ready and in place to communicate when needed. Actually, authenticity is more important than communication skills; an authentic voice is humble, honest, compassionate. (italics added).

The engineering institutions in the UK (and doubtless elsewhere) have press centres, ready to field the appropriate expert when needed. It would be interesting to know if anyone has counted the number of engineers interviewed in the past year on a flagship radio news programme, such as 'Today' in the UK. How does it compare with the number of scientists, doctors and other professions? Are engineers more likely to be hauled over the coals for flooding of the Somerset levels (a major news item in the UK 2 years ago) than to explain an engineering triumph? Are scientists, and their technological achievements, more likely to be presented in a positive light? I have not been able to find any such research, but would love to know the answers to these questions. The press and media are the subject of further discussion in Sect. 7.8. 
Two specific topics in which our ability to communicate with people outside our specialism becomes very important are discussed in later sections. Firstly, setting the performance objectives for seismic standards is discussed in Sect. 5 on engineering standards; we need to make sure the objectives we set are ones that society actually needs and/or wants. The second is lobbying to influence legislation on matters such as the retrofit of earthquake-prone buildings or the introduction of earthquake early warning systems, which is the subject of the next section.

\subsection{The seismic engineering community as lobbyists: the example of the CSSC}

A very direct example of an organisation working at the interface between the technical and wider communities is the California Seismic Safety Commission (CSSC). It was established in 1975 to advise political bodies in California - the decision makers-on ways to reduce earthquake risk. It therefore needs to persuade government at various state and local levels to spend money on improving seismic resilience. It is composed of $20 \mathrm{com}-$ missioners drawn from a wide variety of backgrounds, including taxpayers, local and state government, civil service, fire, social services and utility companies as well as the technical community. This gives it a much wider overview than specialist earthquake engineering societies such as EERI can offer. The CSSC has a very small secretariat, currently headed by an engineering geologist, Richard McCarthy. Its mission was described to me as follows:

The need is to bridge the gulf between the decision making and scientific communities; this gulf is large. Decision makers deal with hundreds of issues, and need concise points; the arguments need to be got across very quickly. Seismic problems are only one of many and competing lobbyists from other fields tend to be more effective in getting their message across. There is a need for communication skills in the seismic technical community. They do exist! - but they must be harnessed and employed. There is a need to 'duck and weave' to get the message across.

The need to get across technical points concisely in this context was also made to me by Tom Tobin, Richard McCarthy's predecessor at the CSSC. Tom told me:

Engineers testifying to committees of the state legislature [during my time as CSSC executive director], where witnesses are given only a few minutes, tended to go off message, and in the end I ceased calling them for that purpose. They tended to overemphasise what isn't known on the issues affecting public policy, whereas the important thing is to concentrate on using what we do know and have. However, the Commission provided a good venue for longer, more technical, testimony from engineers, where commissioner questions could draw out key points.

The CSSC is widely admired for putting across the seismic agenda with effectiveness; one of my Californian interviewees with no direct connection to the organisation said; "CSSC made profound recommendations after [the] Loma Prieta [earthquake of 1989], and they are clearly an organisation to be listened to". As is the case for the equally admired NSET of Nepal, there are no directly equivalent organisations elsewhere in the world, despite some efforts to create them. It is interesting to note that CSSC works to influence at a government level, ('top-down') while NSET is principally directed at a community levels ('bottom-up'). These 'top-down' and 'bottom-up' approaches are further discussed in Sect. 7.3; both are important in dealing with earthquakes. 


\section{Technical fixes and the rational seismic engineer}

\subsection{Technical fixes for dealing with earthquakes}

Each quarter, the magazine of the UK based Royal Academy of Engineering, Ingenia, records stunning current achievements and advances in engineering and presents them in a way that is accessible to a much wider audience than just engineers. Many of the advances it describes address complex societal problems, such as provision of artificial limbs as versatile as natural ones, generating low carbon power safely and cost-effectively, achieving environmentally friendly means for improving the efficiency of agriculture, and so on. It is tempting for the rational minds of seismic engineers to conclude that the way to deal with earthquakes is to find the magic bullets of technology which between them will solve the problem once and for all-provided people can be persuaded to put them into practice.

The advances in seismic engineering have indeed been enormous since I entered the field 35 years ago. The profession now claims that it is possible to design structures to achieve almost any specified level of performance post-earthquake with the level of reliability a client wants. I believe that claim is justified, and is largely borne out by what happened in Christchurch in 2010-2011 (Canterbury Earthquakes Royal Commission 2012). There were of course some notable failures in buildings designed to modern standards, but given that the shaking greatly exceeded the intensity envisaged in the standards, the performance was in line with professional expectations, and most of the comparatively small number of deaths occurred in two buildings with significant defects. Two buildings fitted with new technology did very much better than that; the technical fix of seismic isolation in Christchurch Women's Hospital and of rocking walls and frames with unbonded tendons in the Southern Cross Endoscopy Building represent magic bullets which worked beautifully, and will undoubtedly save lives and reduce damage in the future. Similar examples of successful seismic engineering can be cited from the Great East Japan earthquake of 2011. Laying down a hostage to fortune, I think it is likely that the next great earthquakes in the Tokyo Bay and San Francisco Bay areas will also provide evidence which generally supports the current confidence of the profession, though undoubtedly the evidence will give us much to think about and learn from, just as happened after the Christchurch and Great East Japan earthquakes.

There are of course still major problems to solve for the design of new buildings, even in the context of developed countries such as New Zealand, California and Japan. One is the 'cliff edge effect' - the disproportionately large deterioration in response for a given increase in ground motion intensity. This is a serious problem in seismic engineering because seismic hazard estimates - the basis for design intensities - are subject to such large uncertainties. The much larger than expected ground motions in Christchurch in 2011 is a case in point. The classic 'cliff edge' prone engineering artefact is the tsunami wall; it works perfectly until struck by a tsunami a little higher than the wall. When this happens, not only does flooding reach areas assumed to be safe, but also water pressures now act on the landward side of the wall, which then may fail as the tsunami recedes, and no resistance is offered to a second wave. This is a case of technology apparently offering complete protection to a community, which feels therefore that it does not need to escape to high ground. These factors contributed to the high death toll from the Japanese tsunami in 2011.

Could similar issues affect the solutions currently offered for the seismic resistance of structures? When I started in earthquake engineering, Park and Paulay's (1975) classic 
'Reinforced concrete structures' was less than 10 years old. It introduced and developed the concept of ductility and its achievement through capacity design. This provided a brilliantly simple way of designing buildings that were tolerant of intensities much larger than anticipated, at least to the extent that they protected lives, if not investment. Tom Paulay's Mallet-Milne lecture of (1993), 'Simplicity and confidence in seismic design' sums up the concepts well, and I believe that the outcome in Christchurch in 2011, where capacity design was first proposed, by and large vindicates them. In the years following 1975, the principles of capacity design gradually came to be accepted in the global seismic engineering community, even in California, and have been enshrined in seismic standards worldwide. It is a wonderful way of avoiding cliff edge effects.

I am somewhat concerned that the disadvantage of ductile structures-that they will be damaged, possibly irreparably, by intensities which might not be any greater than the design ground motions - has meant that their advantage is in danger of being overlooked. Sophisticated systems of providing seismic protection must function with very high reliability in the chaotic and sometime unexpected conditions during an earthquake. Under those conditions, failures in original construction quality or subsequent maintenance may cause performance to deviate from what the designers intended. Could some unanticipated failure in just one aspect of the system lead to a rapid deterioration in performance? Of course, most of us are prepared to trust the sophisticated systems which keep modern aircraft in the air; these systems include active control. However, they are very highly maintained, which is certainly not something one could rely on for anti-seismic systems in most buildings, and when things do go wrong in an aeroplane (and they do, for technical or human reasons) the consequences apply to the passengers of a single plane. Failure of a widely used anti-seismic system might potentially affect many buildings in a city or region.

Terry Cannon (2015) points to another aspect of large and expensive technical fixes for disaster reduction - a number of elite groups, remote from the people for whom the technical fix is intended, favour them because they can profit from a share of the large amount of money changing hands. Politicians might get kickbacks, corporations get valuable contracts and the transactions are good for the business of lending banks. This activity, Terry Cannon points out, "takes very little account of how these activities will integrate with local people's needs and priorities.... The culture of tech-fix organisations fails to understand that problems that have predominantly political, economic, social and cultural causes are not guaranteed to be fixed by proposed solutions that do not address these causes (and which can often reinforce the very power relations that are part of the problem as well)".

\subsection{Technical fixes for developing economies}

Perhaps the most pressing need is for magic bullets directed towards producing appropriate, low cost solutions to earthquake resistant houses, particularly in rural areas of developing countries. The technology must suit not only the materials and financial resources that are locally available, but also the construction skills. It must be in harmony with the lifestyle and cultural traditions of the local community. Finally, there must be some way of getting the technology to take root and spread beyond a few demonstration houses built with the aid of foreign experts who do not have to stay and live in them. Solving all these issues clearly needs skills in addition to the technical ones of seismic engineering.

A number of organisations exist which are trying to address these issues. The work of NSET in Nepal has already been mentioned. NSET has the deep advantage that it is part of 
the society in which it is working and it lays great emphasis on the need for patient, long term community work. NSET's director, Amod Dixit, told me that it is open to using new methods of construction, but sees no point in introducing them just for the sake of being European; the default position is to use traditional methods where appropriate. The earthquake problem, he says, is one that is rooted primarily in social and political issues, rather than technical ones, and Borchers (2017), reporting on school construction in Nepal, makes the same point. The quest for improving the earthquake resistance of rural communities in places like Nepal is therefore seen not as one of finding magic bullets, but of engaging in a gradualist approach which modifies local attitudes and improves local skills.

Build Change and GeoHazards International (GHI) are two other examples of organisations which seek to improve the resistance of buildings and communities in developing countries to earthquakes and other natural hazards. Both are based in the USA. One of GHI's projects is the 'Made in Bhutan earthquake desk' (https://youtu.be/ KUONYzHQrjo), a simple school desk made from a steel supporting frame surmounted by a wooden table top. It is designed to withstand the impact of heavy debris, and so provide some protection to schoolchildren against the collapse of their school; they are trained to 'duck, cover and hold on' immediately they feel the ground shake. Not exactly a magic bullet, but it is an elegant example of appropriate, culturally sensitive technology; the desks are locally manufactured but also provide a useful every-day function; their operation is very easy to understand and they serve as an interim, low-cost measure until the ultimate goal is achieved of ensuring that Bhutanese schools buildings are structurally sound and earthquake resistant. That ultimate goal is however seen as important and GHI consider school building and strengthening projects as one of their priorities. ${ }^{3}$ The rationale for this emphasis is not just the obvious one that protecting schoolchildren is so important. Building or retrofitting schools so that they can withstand earthquakes is a way of introducing those techniques more widely into a local community. Schools have these features:

- A school's hierarchical organisation, with a head teacher as the single person in charge, makes it easier to ensure a consistent, well implemented outcome.

- Many different people from the community are involved in a school-not just the children and staff, but also the parents. Therefore, information about seismic resilience and improvement practice spreads widely.

- The local masons trained in aseismic techniques can then employ these skills on other types of building, like houses.

- There is evidence that many people are prepared to devote their time, effort and resources to improving the seismic resilience of their local schools. Anne Sanquini ${ }^{4}$ conducted interviews of 761 people living in rural communities in the Kathmandu Valley. On a scale of 1 (very unlikely) to 6 (extremely likely), the average score was 4 for getting personally involved in tasks such raising money and contributing to construction tasks for improving the earthquake resistance of their school.

Of course, the building methods that are used have to be technically sound, but what the approach of targeting schools represents is a magic arrow to the heart of a community, rather than a magic technical bullet.

\footnotetext{
3 For further details, see http://www.geohaz.org/safeguarding-schools.

4 Personal communication with Anne Sanquini during 2017. The full research is described in Sanquini et al. (2016).
} 


\subsection{Technical fixes for disaster response}

One area where new technologies have had a striking impact in both the developed and developing world is disaster response. Interestingly, the technologies have mainly involved disciplines other than structural engineering, but nevertheless seismic engineers have used and benefited from them. The possibility of using remote imaging from satellites and aircraft to assess the damage caused by earthquakes has been available for some time, but it came into its own after the Haïti earthquake of 2010. The international community quickly became aware that a very damaging event had struck Port-au-Prince and its surroundings, but communications to and around the area were all but impossible in its immediate aftermath. It was the examination of satellite images by a volunteer team of experts spread around the world, networking by internet, that produced the first hard data on the extent of the tragedy, and the consequent needs for the relief operations (Ghosh et al. 2011). No doubt in the future increasing use will be made of drones, discussed in the context of postearthquake reconnaissance missions by Stone et al. (2017).

The ShakeMap system (Worden et al. 2010) uses ground based sources to build up a picture of the scale and extent of damage immediately after an earthquake. It makes use of the easy and rapid connectivity provided by the internet and fast computer speedsessentially twenty first Century innovations - to create its first damage maps a few minutes after an earthquake has occurred, but these are regularly updated as more information becomes available. The maps are based on direct measurements of ground motion as recorded by accelerometers, indirect estimates from ground motion prediction equations using the magnitude and location of the earthquakes, and citizen reports of what they have felt and seen as a result of the earthquake. There is little doubt that ShakeMaps have greatly assisted emergency response.

A new source of information creating such maps makes use of the fact that almost everyone now carries mobile phones with them; they are widespread in the developing world as well as the developed one. Smart mobile phones are equipped with accelerometers which Kong and colleagues (2016) have shown can record ground motions due to magnitude 5 earthquakes at distances of $10 \mathrm{~km}$. With mobile telephony data links, the data from the phones of thousands of citizens could be fed into a ShakeMap-like system to make the maps even more valuable for planning the disaster response.

A demonstration that this works in practice in a damaging earthquake has not yet been obtained, but mobile phones had another very positive contribution to response in Kathmandu after the 2015 earthquake, and it was one that surprised me. A senior doctor at the city's largest hospital told me that a major problem was co-ordinating response with other hospitals. However, the mobile phone network held up well, and that was essential in enabling co-ordination to work as well as it did. It is likely that other elements of the emergency response benefited in a similar way. Commercial competition has ensured that there are three competing mobile phone networks in Kathmandu, contributing diversity and hence resilience to the system. However, if the intensity of shaking had been enough to destroy essential elements of the system, or if a surge in use had saturated it, then there might have been a 'cliff-edge' reduction in the ability to co-ordinate emergency response across the city.

These twenty first century technical contributions to improving disaster response have, I suggest, not only been successful but have also been much more universally applied than the purely structural innovations of the same period. The structural measures work very well where they are applied, but they are not incorporated in the vast majority of buildings, 
which therefore have lower and often inadequate seismic protection. By contrast, disaster response measures have the potential to protect everyone, irrespective of the type of buildings they live in. However, technical fixes to assist earthquake response are not without issues. To conclude this section, I want to discuss earthquake early warning systems (EEWS). These represent a further technical fix to improve response but may be more problematic than the others I have described. EEWS works because data transmitted by modern communication systems travels much faster than seismic waves. Accordingly, if there is a network of seismometers immediately around the source of the earthquake, it can establish its size and location almost instantly, and then relay this information to surrounding areas. If the earthquake appears potentially destructive, then appropriate actions can follow; for example, emergency braking can be applied to high speed trains and other high risk systems can be shut down. A site $50 \mathrm{~km}$ from the source would receive an advance warning of only $10 \mathrm{~s}$, but this sort of system is being actively considered for Mexico City, Istanbul, California and elsewhere and has been successfully used to halt high speed trains in Japan. Laurie Johnson and her associates (2016) prepared a detailed report on EEWS for the California Seismic Safety Commission; although they conclude there is much work to be done before implementation, they are generally positive about its potential benefits in a Californian setting. The media, too, have been very enthusiastic (Fox News 2017). There is however a feature of Californian society that makes some much more cautious. A well placed Californian I talked to said:

Earthquake early warning systems are a great idea, but California society is much more litigious than Japanese society. We have attorneys, the Japanese don't. If there is a false warning, panic and mayhem could ensue. Government has immunity for negligence - but not gross negligence, and a seriously wrong warning could amount to that. Major companies who might otherwise have wanted to become involved don't have any immunity, and so are reluctant, because of the risk of being sued if things go wrong.

Laurie Johnson's report, cited earlier, recognises the danger but overall still comes out quite strongly in support of developing EEWS for California. The more cautious response just quoted is a powerful illustration of the complex interactions between sophisticated technology and the makeup of society-interactions that affect how earthquakes are dealt with.

\section{Seismic engineering standards}

\subsection{The role and effectiveness of standards}

Seismic standards address issues of preparedness-things that promote resilience before rather than after an earthquake strikes - and this is rightly seen as key to their importance. They are a means of sharing and spreading best practice, and thus a tool to help skilled practitioners design 'useful artefacts' which are fit for their purpose. But in addition to this positive function, there is a second function which is often confused with the primary function. Standards provide prescriptive minimum requirements against which builders, engineers or owners must demonstrate compliance. In the context of seismic engineering, these 'minimum requirements' might include the avoidance of weak/soft storeys, setting minimum material strengths or specifying required patterns of detailing for the reinforcement. 
However, it is necessary to distinguish between industry standards of best practice and minimum legal requirements. Scott Steedman, a geotechnical engineer by background with very extensive experience of European and international construction regulations and standards, told me:

Setting out a legal requirement is very different from encouraging better practice. Although industry standards can be used very effectively to support the delivery of public policy (for example as a means of compliance), they are not a substitute for a well-drafted, legally based technical regulation. The lack of clarity over what is a minimum requirement in law and what is an industry standard of better practice has led to widespread confusion amongst stakeholders over what is mandatory and what is voluntary good practice in any given situation.

There is no doubt that improved industry standards have led to increased seismic protection in developed countries like the USA, Japan and New Zealand; Robin Spence (2007), in his Mallet-Milne lecture 'Saving lives in earthquakes', presents plenty of evidence for this. Standards are a great way of sharing the best information among a community of the willing, but they are ineffective if not observed. Without clear direction from policy makers on which aspects of a standard will be deemed to satisfy a legal requirement and without an effective means of enforcing the law, standards cannot provide a safety net for all. Because of this lack of a clear definition of the minimum legal requirement coupled with inadequate enforcement, and for a variety of other cultural, political and economic reasons, standards alone have been rather ineffective in developing countries. Jitendra Bothara and Richard Sharpe (2003), who both make appearances later in this section, explore the causes for this, particularly in relation to Nepal, while a recent authoritative report by Mouiller and Krimgold (2015) for the World Bank proposes a range of solutions. They consider the four most important priorities for the development of construction standards in low and middle income countries to be:

1. orienting regulatory and governance reforms toward compliance advice and support rather than just police enforcement;

2. developing the capacity of national and subnational institutions;

3. focusing on creating building standards that are appropriate for the poor and vulnerable;

4. promoting innovations for effective building controls, and in particular making the practical administration of controls simpler and less bureaucratic.

It is noteworthy that the first item on the list focusses on emphasising a positive rather than a negative approach; carrots are better than sticks. The positive aspects encourage the development of skills and help to ensure improved outcomes, whereas enforcement is associated with ways, possibly corrupt ones, of avoiding rules. It should be further noted that items 1, 2 and 4 on the list address what Mouiller and Krimgold call the 'regulatory framework', which they see as of key importance in making construction standards and land use controls effective. Only item 3-creating appropriate standards-is directly connected to the technology of seismic engineering; however, seismic engineers need to be involved in all four items, because they can advise regulators on the most effective way to distinguish between minimum legal requirement and better practice, and can also advise on the practicalities of implementation. The issue of what might constitute an appropriate standard and corresponding regulatory framework for a low income country is something I return to in Sect. 5.4. 


\subsection{The scope of seismic construction standards}

Seismic standards raise particularly difficult questions about their scope; should they only cover life safety issues or should broader issues be included as well, such as limiting the economic consequences of an earthquake? The questions raised are more straightforward to resolve when designing buildings solely for gravity loads. This is due to economic considerations, because inadequate design for serviceability issues, such as cracking or excessive settlement, would be quite likely to become apparent soon after construction and long before there was a serious threat to stability. If such serviceability issues arose, the owner would then want redress for the fact that the structure was not fit for purpose. So provisions to ensure serviceability under gravity loads are accepted as an essential part of building standards; life safety considerations are of course important too, but are less likely to govern.

These questions are harder to resolve for seismic standards, because a damaging earthquake may only threaten a building years after it has been built, and possibly not at all. The need for protection of life in a rare earthquake is universally accepted. However, although serviceability issues are nominally addressed in current standards such as Eurocode 8 (CEN 2004), it is usually done in a perfunctory and rather unsatisfactory way. There has been much debate during the current revisions to Eurocode 8 as to whether to allow each country adopting the Eurocode to decide if the seismic serviceability requirements should be a mandatory requirement of the standard, i.e. applied to all buildings, as at present, or if they should be changed to becoming discretionary and so only applied if the building owner wants them to be, for economic or other reasons. The question of whether the standard is or should be 'regulated' is a policy matter, not a technical matter. In almost all cases, European standards are voluntary. Standards may be obligatory, in the sense of being a contractual requirement imposed by a client, but they are not technical regulation imposed by government.

In the context of the law, governments generally intend seismic building regulations to protect the 'welfare' of its citizens. In New Zealand and California, it appears that this is interpreted as being limited to addressing life safety issues. However, it is clear that the welfare of many more citizens of Christchurch was affected than the comparatively small percentage who were killed or injured by the 2010-2011 earthquake sequence. Many had to move house, temporarily or permanently, the closure of the Central Business District had a very significant effect on employment and the loss of cultural heritage buildings also had a profound impact. All these destabilising events affect welfare in some way, and probably had some impact on the reported significant increase in mental health problems (CERA 2014) following the earthquakes. If regulations are necessarily limited in their capacity to address the wider, 'better practice' aspects of resilience, could standards be used more effectively as an enabler to improve the resilience of communities to earthquakes, including their economic prospects, religious and educational facilities, cultural heritage and so on? These are important questions whose answers directly affect the technical content of standards. How the questions are resolved I discuss in the next subsection.

\subsection{Making standards}

Seismic engineers write seismic standards; they use their professional skills to develop tools for ensuring that the performance goals set out in standards are met with adequate 
reliability. However, the discussion so far makes it clear that issues beyond merely technical ones are involved, and it is appropriate that debate about appropriate performance should widen beyond the technical community to include regulators, acting as representatives of the political will of the people and other stakeholders, such as societal, environmental and labour representatives. This is widely accepted; for example, the European Standardisation Organisation CEN has formal procedures for such consultations.

However, there are two inherent problems, at any rate in the context of seismic standards; firstly, standards by their nature operate at a national or at least regional scale, and so are inherently 'top-down', rather than 'bottom-up'. How then can the real needs and aspirations of ordinary citizens be incorporated? Secondly, their technical nature makes them difficult to understand except by specialists. The consequences of the recent earthquakes in New Zealand and Chile suggest that these are issues that certainly need to be addressed. Thus, the provisions of standards in both meant that code-compliant buildings protected their occupants rather well, but some buildings were so badly damaged they had to be demolished. Ramon Verdugo told me "The 2010 Chile earthquake induced heavy damages in some new apartments generating many people without home, but they have to continue paying their apartment loans to the banks".

In practice, involving non-technical people in the drafting of standards is not easy, even in a rather close-knit country like New Zealand. Partly this may be because complex technical concepts are involved, such as probability and reliability; perhaps it is also because not enough engineers are able to explain these concepts in ways that non-technical people can relate to. After the 2010-2011 Canterbury earthquake sequence, new regulations began to be drafted and a parliamentary select committee was set up to oversee the process. A well-placed New Zealand informant told me: "The main work is done by the technical people; when technical matters are discussed, most of the non-technical people leave and the general public haven't a clue”. In California, the CSSC, discussed in Sect. 3.7, tries to involve politicians in the setting of seismic standards and regulations, but it appears that much of its most effective work was done in the immediate aftermath of the Loma Prieta earthquake, over 30 years ago.

Beyond the field of earthquake engineering, however, it appears the wider community is beginning to have a closer involvement in developing industry standards; Scott Steedman told me:

In other fields, for example in smart cities, the development of better practice standards has followed a different path, a path that may provide lessons for earthquake engineers and other technically focused communities. Smart city projects will clearly require hundreds of new standards addressing highly technical issues. But as this is a new field, there was an opportunity to take a holistic approach and to ask city authorities themselves what they needed by way of better practice standards to accelerate their work programmes. The city authorities asked for standards of terminology, guides for city leaders, ${ }^{5}$ framework and decision making, even business case standards. These new types of standard were made in a cooperative effort by all the affected stakeholders, including the technical experts.

In Europe, the same CEN sub-committee is responsible for producing all parts of the seismic Eurocode 8, both the parts which set the overall performance and also those dealing with detailed technical issues. The latter are rightly the preserve of the expert technical community, but the former should be opened up to wider debate. Although there

${ }^{5}$ For further details, see www.bsigroup.com/en-GB/smart-cities/. 
are effective mechanisms for involving political or other non-technical communities in standards making, as in the example of smart cities, these have not yet been applied nearly effectively enough in the setting of seismic performance standards. One solution would be that the parts of Eurocode 8 dealing with performance issues should be dealt with separately from the technical parts, both with respect to drafting and to circulation for comment. The British Standards Institution (BSI) may be able to help here; Scott Steedman, its Director of Standards, told me:

BSI in its role as the national standards body and UK member of [the International Organization for Standardization] ISO and CEN could readily facilitate that process for UK and international experts. As a former earthquake engineer and now Director of Standards responsible for the national standards body, I would be delighted to facilitate a discussion with the earthquake engineering community over how the wider issues of earthquake performance of the built environment could be the subject of a consensus of stakeholders, how this may vary in different parts of the world and how framework standards may be developed to enable national, regional or local authorities to adopt such standards in conjunction with appropriate technical regulation.

There are very effective mechanisms for involving non-technical communities in consensus building - it is one of the fundamental requirements of formal standards making. Where a technical community has 'colonised' the space it can be more difficult to persuade them that framework standards are valuable - but it is clear that they would be very valuable in the context of earthquake engineering. Perhaps this could be the missing key that would break the cycle, together with a better understanding of the different role of regulation from the that of standards.

\subsection{Appropriate standards for low-income countries}

It is a fundamental humanitarian principle of the European enlightenment that humans have equal value, irrespective of their race, colour or creed. The welfare needs of Nepalese peasants should therefore be taken just seriously as those of San Francisco city dwellers, even though their cash income is two orders of magnitude less. There are powerful arguments, though, to suggest that standards in San Francisco should be quite different from those in Nepal. The sophistication of Californian standards is likely to be unnecessary for most conventionally designed engineered steel or concrete buildings in Kathmandu; in any case, since published standards represent a consensus of the technical experts on what is 'safe' practice for typical structures, higher standards can always be used in Kathmandu for particular buildings that need them. However, it is in a rural setting that the difference in needs is greatest, because rural buildings in Nepal are of course quite different from those of downtown San Francisco. But it is more than that; the primary concern in rural Nepal is not to ensure a certain level of welfare for its citizens but to encourage the adoption of any sort of seismic measure at all. Jitendra Bothara, an earthquake engineer and Nepali national now based in New Zealand, is quite clear; he told me "It's better to aim for achieving 50\% of 'ideal' standards if they are likely to be implemented than $90 \%$ of those standards if they are very unlikely to be implemented".

A pioneering example of a standard with this approach is the Nepali seismic standard (DUDBC 1994) which predated the 2015 earthquakes. Drawn up by a team led by an expatriate New Zealander, Richard Sharpe, it allows for four layers of sophistication: 
- International state of the art procedures-the most sophisticated level.

- Quantified procedures for professionally engineered structures.

- Rules of thumb for reinforced concrete frame buildings with or without masonry infill and for load bearing masonry buildings.

- Guidelines for weak masonry and earthen rural buildings - the least sophisticated level.

A review of the 1994 Nepalese seismic standard is currently being carried out; it is after all over 20 years old, and it would be surprising if there were no attempt at a revision incorporating lessons from the Nepalese earthquakes of 2015. However, and very significantly, in all my recent discussions in Kathmandu and elsewhere, no-one considered that the earthquakes had revealed any serious technical flaws in the 1994 code, although some changes for engineered structures were thought desirable. It will be interesting to see if the four-layer structure of the standard survives the post-earthquake review. Just as important, it will also be interesting to see if the review recommends changes to the regulatory framework, and if consideration has been given to the sort of regulatory issues raised by Mouiller and Krimgold (2015) in their World Bank report, cited earlier, and to the associated fundamental issues raised by Scott Steedman in my discussions with him.

\section{Earthquake insurance and other financial measures}

\subsection{The role of insurance in dealing with earthquakes}

Table 4, taken from figures prepared by the Swiss Re reinsurance company, gives an estimate of the insured losses from earthquakes in seven earthquake prone countries for the period 1970-2011. It compares them with an estimate of the total direct losses the earthquakes caused-i.e. the cost of reconstructing the facilities damaged by ground shaking, tsunami and liquefaction, but excluding indirect costs such as business interruption and other societal costs. 90 earthquakes are covered by the table, but most of the losses come from a much smaller number of events. In particular, 2011 had the highest single-event earthquake-related economic loss ever recorded-the Great East Japan earthquake and the tsunami it triggered. The Northridge earthquake of 1994 and Kobe earthquake of 1995 were also major contributors to total loss.

Two things are immediately clear from the table. Firstly, the amount of money that earthquake insurance contributes to reconstruction efforts can be considerable. Secondly, that money is very unevenly distributed, with Table 4 showing a huge range in the ratio of insured to economic loss. Nepal is not included in the table, but it is estimated that less than $1 \%$ of the losses from the 2015 earthquake were covered by insurance and the same is true of the Haiti earthquake of 2010. Compare that with $80 \%$ in New Zealand, almost all related to the Christchurch events of 2010-2011.

The variation in insurance cover reflects the different factors which apply to different countries. In New Zealand, the Earthquake Commission (EQC) provides a government backed, compulsory scheme and insurance penetration is exceptionally high. The California Earthquake Authority,(CEA) although not obligatory and privately funded, is publicly managed. In Turkey, the situation is somewhat similar; the Turkish Catastrophe Insurance Pool (TCIP) is a government backed, privately managed scheme which ensures that all private homeowners can obtain earthquake insurance at reasonable rates if they want to, but they are not obliged to do so and the take-up has been greater in urban than in rural areas. In Chile, earthquake insurance is a condition of getting a mortgage; once this is 
Table 4 Insured and economic losses in seven earthquake prone countries for 1970-2011 taken from: Bevere and Grollimund (2012)

\begin{tabular}{lllll}
\hline & $\begin{array}{l}\text { Number of } \\
\text { events }\end{array}$ & $\begin{array}{l}\text { Insured losses } \\
\text { (US\$bn) }\end{array}$ & $\begin{array}{l}\text { Economic losses } \\
\text { (US\$bn) }\end{array}$ & $\begin{array}{l}\text { Insured losses } \\
\text { Economic losses } \\
(\%)\end{array}$ \\
\hline New & 3 & 17 & 22 & 80 \\
$\quad$ Zealand & & 25 & 64 & 38 \\
USA & 13 & 9 & 34 & 26 \\
Chile & 5 & 1 & 11 & 10 \\
Mexico & 11 & 40 & $373-463$ & $9-11$ \\
Japan & 24 & 2 & 30 & 5 \\
Turkey & 26 & 1 & 50 & 2 \\
Italy & 8 & &
\end{tabular}

Losses are indicated in billions of US dollars at 2011 prices

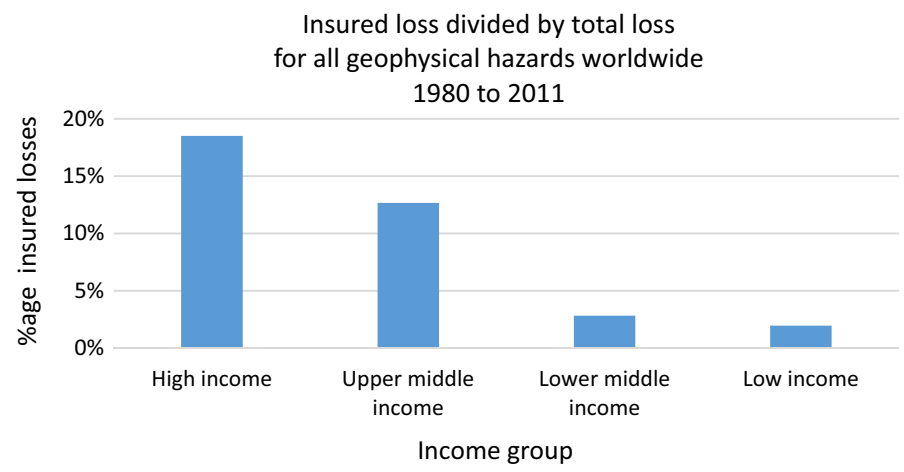

Fig. 2 Ratio of insured to total losses for all geophysical hazards (includes tsunamis and landslides as well as earthquakes) 1980-2011. Source: NatCatSERVICE, Munich Re 2017 (http://natcatservice.munichre.com/)

paid off, many home owners do not continue the cover. Bevere and Grollimund (2012) report that in Italy "the popular perception is that the government will provide relief and reconstruction in case of an earthquake, and private insurance penetration is low"; they report a "notoriously low penetration" in Japan, but Anselm Smolka (private communication) advises that things have changed in the residential sector and the penetration is now significantly higher, although it remains low for the commercial sector. In Haiti and Nepal, the negligible penetration is undoubtedly linked to their being two of the poorest countries in the world. Figure 2, although covering a slightly different period from Table 4, suggests that a similar trend applies worldwide.

Seismic engineers may not be able to exert much influence on the inflow of insurance or other types of money into an area struck by an earthquake, but it affects their work in a number of ways. In the next sections, I discuss the effectiveness of earthquake insurance in terms of risk transfer, risk reduction and risk quantification. 


\subsection{Risk transfer}

The most obvious and direct way in which earthquake insurance affects the ability of a society to deal with earthquakes is through risk transfer. The insurance industry operates by collecting relatively small annual premiums on a regular basis from a wide geographical spread of clients. However, it is only when a disaster strikes that insurance companies make payouts, which will typically be many times larger than the annual premiums of the people who receive the payouts, but which is received by only a small number of the insurers' clients. In this way, the financial consequences of the disaster are shared in time and space. This spatial sharing is increased further by the reinsurance companies, which transfer risks between insurance companies on a global basis.

Risk transfer plays its main role in recovery after an earthquake; ${ }^{6}$ Writing as professionals within the industry, Bevere and Grullimond (2012) state: "The [insurance] industry plays a key role in post-disaster recovery". There can be little doubt that this is true (although quantifying its effects proves to be harder); having substantial amounts of money coming into an earthquake stricken region must affect its recovery and the way in which a region bounces back after a disaster. Anecdotally (and undoubtedly) the influx of substantial amounts of money into New Zealand following the 2010-2011 Canterbury earthquake sequence had a very significant effect on the national economy, particularly since much of the money came from reinsurance companies based outside New Zealanda general feature of insurance money, given the global nature of the reinsurance industry. Interestingly, most of the insurance money coming into New Zealand is reported as having been spent on goods and services sourced in Auckland and Wellington, where the economic impact was therefore greater than in Christchurch itself, at least in the short term. These are factors well outside the sphere of direct influence of engineers, but most UK civil engineers will have been aware of the resulting increased demand from New Zealand for their services in the last 6 years.

Direct quantitative evidence of a link between insurance payouts and speed of recovery is harder to obtain; Stephen Platt (2015) and his colleagues did show a correlation after the Northridge earthquake of 1994, but found it difficult to get extensive evidence. However, evidence from other fields suggests that the direct cash flows which the insurance payouts represent should be very effective; it is the 'bottom up' measure par excellence, giving rapid help directly where it is needed to be spent according to the recipient's needs, untrammelled by outside interference. There is evidence that shows that such payments made directly to those that need it has proved its worth in other fields, too. For example, a UK government financed scheme ${ }^{7}$ giving money directly to those affected by drought in northern Kenya has proved a highly effective measure, and Tim Harford (2015) provides further examples of the effectiveness of direct injections of cash at a local level being an effective development tool.

The Kenyan scheme quoted above, and those like it, are not of course linked to insurance, and indeed apply to places where insurance penetration is likely to be very low. There are other mechanisms by which external money and resources can flow into an area after a disaster, the most obvious being aid provided by governments and international aid agencies. This happens in developing countries; think of the hundreds of separate (and

\footnotetext{
${ }^{6}$ The ability to recover effectively is an important contributor to resilience, though of course conditions immediately before the earthquake are very important contributors to resilience, too. In Sect. 7.2, I return to a discussion of recovery and resilience.

7 For further details, see http://www.hsnp.or.ke/.
} 
uncoordinated) overseas aid organisations that descended on Port-au-Prince after the 2010 Haïti earthquake. But it happens in highly developed countries, too; think of George W Bush's pledge to rebuild New Orleans after Hurricane Katrina in 2005, irrespective of whether the recipients had insurance cover or not. There are difficult issues here, which engineers should at least be aware of, because they are caught up in them, even if they cannot solve them. Why should I bother to protect my home against flooding if I know that the government will bail me out if there is a flood? This is the issue of 'moral hazard'. Is a pledge made after a disaster has occurred the best way to 'deal with' it, particularly if made by a politician facing growing unpopularity? And did the large sums of money coming into Port-au-Prince in 2010 address Haiti's real needs? Was it perhaps counterproductive in inducing, or perhaps reinforcing, a culture of dependency? Clarke and Dercon (2016) in their book 'Dull disasters' have much to say about 'moral hazard' and the drawbacks of a 'begging bowl' approach to disaster relief. Their message is that direct interventions are only really effective if they are planned before disaster strikes, and are not a hurried response in the crisis conditions after it has happened.

\subsection{Risk reduction}

Earthquake insurance is important in promoting rapid recovery after an earthquake, but it can also play a part in limiting the damage that occurs in the first place. One way is the provision of advice to homeowners about how to prevent or limit damage; it is in the insurance company's interest to limit the value of claims, and organisations such as the CEA in California and the EQC in New Zealand offer plenty of good advice on their websites. But advice can easily be ignored, and there are more direct ways to influence buyers of insurance. According to Robert Muir Wood (2016), an early attempt to use insurance to reduce risk, and not just transfer it, was in 1901, when Leopold Heath offered substantially reduced premiums for smallpox insurance to people who had been vaccinated. Suddenly, insurance becomes linked to preparedness for a risk, and not just the response once it has occurred. We are familiar with conditions on our domestic fire and burglary policies which require smoke alarms, fire doors and sophisticated locks; finding that we can reduce our premium if we install a burglar alarm may encourage us to do so. Would it not be an obvious step to link earthquake insurance premiums to the measures we take to protect our property from seismic damage? This transports us from the world of seismic engineering to that of the financial markets.

An obvious way of doing so would be to establish a starred rating system for seismic resistance, in the same way as is done for environmental rating. Thus, performance would be excellent in a five star rated building but poor with only one star. A rating system could form the basis for setting more favourable insurance premiums for highly rated buildings. There might be other financial incentives for achieving a five star rating, such as lower interest on mortgage loans, because highly rated systems would pose a lower risk for the lenders, and tax incentives like lower property taxes, in principle funded by reductions in future losses to the local community. There are other benefits, too; knowing the seismic risk of a property might in itself induce homeowners to reduce its vulnerability if the rating was poor, even in the absence of a requirement to upgrade, especially if the homeowner had recently heard about a damaging earthquake. The rating system of a property might even influence its value and saleability. Note that none of these claimed benefits would be likely to cut much ice in Haïti or Nepal.

Several seismic rating systems have been proposed, among them SEAONC (2011), Almufti and Willford (2013) and Calvi et al. (2014). In 2014, the Los Angeles Times 
reported "Mayor Eric Garcetti wants buildings across LA to be graded for their seismic safety in an ambitious plan to help residents understand the earthquake risks of their offices and apartments" (Los Angeles Times 2014), so the idea has some political momentum, too. There are however some formidable difficulties. In principle, it should be relatively straightforward to rate newly built structures in areas where there are well enforced seismic standards, based on certified compliance with the building regulations. Even here there is a problem, because, as Smolka (2014) points out, seismic standards are mainly concerned with ensuring life safety rather than preventing economic loss. Proving that a damaged building did in fact comply with standards could be difficult, too.

For existing buildings, it is much harder. To calculate the annual risk of earthquake damage to a structure requires an estimate of both the hazard (the probability that damaging ground motions might occur in any 1 year) and the vulnerability of the structure (its proneness to be affected by ground shaking). It is of course the broad seismic engineering community which provides some of the skills for both these calculations. Although seismic hazard estimates are not easy to make, and are affected by many known and unknown unknowns, high quality estimates of hazard on reference rock sites are easily and freely available for most — not yet all—inhabited parts of the earth. The necessary adjustments for surface effects - the influence on ground motion of the soil overlying bedrock at a site and its topography - is often more difficult to make but are usually possible, albeit with varying degrees of confidence.

It is in the structural vulnerability estimates that the problem lies. The class of building ' 2 storey brick masonry residences' covers an enormous range of possibilities, even within one country. Apparently very similar buildings may have small differences in layout and construction quality which radically alter their ability to stand up to earthquakes; the same is true for modifications carried out since construction. Generic 'vulnerability curves' exist for many classes of building; these give estimates of the average loss that might be expected in a large group of buildings belonging to the same class for a given intensity of shaking. They also estimate the variability of losses that might be expected within the group. The problem is that this variability is always very large, so that a vulnerability curve is a poor tool for making precise adjustments to the insurance premium for a particular building. Obvious defects like soft storeys or poorly attached items of building contents are usually quite easy to spot but to get high confidence in assigning a high rating score to a building is much harder.

For major industrial facilities, where insurance premiums are sufficiently large to be worth negotiating, and where there are strong commercial incentives to reduce the risk of business interruption, insurance companies have negotiated changes to premiums, based on a detailed (and costly) assessment of risk, possibly resulting in an agreed upgrade plan. For private houses and small companies, it seems that currently the effort this would involve is not outweighed by the perceived benefit. Anselm Smolka, someone with long experience of working within the insurance industry, told me that he had tried-and failed-to promote the same approach to seismic insurance as to fire insurance, by linking the cover provided, and its costs, to protection measures. "It has been a miserable job!" he told me; "the way the industry sets seismic premiums is currently very crude, often limited to classification by three classes of buildings and four hazard levels (sometimes not even including soil effects). Insurance premiums are subject to huge market pressures and so tend in any case to be depressed". In his contribution to a book on disaster risk (Smolka 2014), Anselm Smolka writes:

Risk-adjusted premiums involve tariff schemes that reflect the actual risk level commensurate with the location and the constructional characteristics of the insured 
object. Such tariff schemes are increasingly being used on a global scale, building on the support provided by advanced loss-modelling software. But the correct application of such schemes poses a problem, and in actual practice, rates are usually still dictated simply by competition. Sometimes, for instance, rebates are given for alleged compliance with anti-seismic building regulations. Often, however, the alleged code compliance has not been checked by insurance engineers or agents and does not in fact exist.

Robert Muir Wood (2016) foresees a future where this will change, where all buildings display prominently their rating for earthquake resistance, where new technologies have enabled rapid categorization of building resistance and rapid retrofitting techniques to upgrade it, and where 'resilience brokers' negotiate the loans required to achieve the upgrading needed. This could possibly be a realistic future for Los Angeles in 2030 but I fear it will take a little longer for Kathmandu or Port-au-Prince.

\subsection{Risk quantification}

Authoritative flood risk maps for the UK are freely available online. They do not stop people from buying houses in high hazard areas, but there is at least an expectation that the maps may lead to changes in behaviour in some people; thus, they might be prompted to take measures to prevent or reduce flood damage before it has occurred, or to include flood risk in the factors they consider when they move house. The wide availability of the maps also probably puts pressure on politicians to consider flood risk when setting policy, even if it has not resulted in the authorities preventing all new construction in areas where flooding is likely. Making information about seismic risk widely available in the same way might also be expected to change the behaviour of private citizens and the politicians that govern them.

Maps showing seismic hazard, for example expressed as the ground shaking associated with a certain return period, are indeed widely available. However, a knowledge of what damage that shaking will cause is also essential, because the outcome varies hugely between buildings; when subjected to the same intensity, some buildings will hardly suffer while others will collapse. The previous section described how difficult it is to make a reliable estimate of this for an individual building. However, estimates of the risk posed by a large portfolio of buildings poses far fewer problems, because the inherent variability between individual buildings becomes averaged out. This is a subject of great interest to insurance companies because what they have to pay out is the sum of losses in all the buildings they cover, rather than a particular one, and it is this total payout that affects their bottom line. Catastrophe modelling-estimating portfolio losses due to various hazards including earthquakes - is a big industry, in which the seismic engineering community plays an important part. The insurance industry uses the results of catastrophe models to set their premiums, which therefore become a pricing mechanism for seismic risk. Thus, risk quantification for insurance purposes provides the rest of the world with an objective, easily compared measure of seismic risk, although it must be admitted one that is still subject to considerable uncertainty.

These estimates of 'portfolio' or aggregated risks may not be of too much use to individual homeowners but public authorities have shown a lot of interest, because they direct attention to the districts where improvements are most needed, and where most damage is likely to occur, which assists their disaster preparedness plans. The paper by Mauro Dolce (Dolce et al. 2012) and his colleagues at the Italian Civil Protection 
Department discusses this type of use. It is therefore relevant for both disaster prevention and for disaster response.

Thus the insurance industry, in its geographical pricing policy for seismic insurance cover, provides a direct source of risk information, but the industry has strong links with another source. The Global Earthquake Model (GEM) was established in 2009 with the ambitious aim of "helping to create a world that is resilient to earthquakes by:

- becoming the world's official, most complete source of earthquake risk resources; and hence a globally accepted standard for risk assessment

- ensuring that GEM products find application in earthquake risk management worldwide".

Its work is organised in three main areas:

- Seismic hazard to create state of the art tools for seismic hazard assessment, and then, working with partners across the world, use them to map hazard across all the inhabited areas of the world.

- Seismic risk to quantify the vulnerability of common building types worldwide, and then, again with assistants of regional partners, establish inventories of buildings in major urban centres and map the risk as widely as possible worldwide.

- Integrated risk to develop tools that quantify the relationship between socio-economic factors and seismic risk, recognising that these factors strongly influence the impact that earthquakes have on communities. This relates to a principal theme of this paper.

The goal of the seismic hazard programme to achieve global mapping is nearing completion, and the tools developed have been widely influential, including in a number of government agencies responsible for producing official seismic hazard maps. The seismic risk programme is well advanced, and partnerships with public authorities in many parts of the world have the potential to result in real improvements in public policy. The integrated risk programme is the most ambitious and least advanced; unlike the hazard and risk programmes, not much work had previously been done in this field. The California Seismic Safety Commission has funded a GEM project (Despotaki et al. 2017) investigating the influence of socio-economic factors on the speed of housing repair after the 2014 South Napa Earthquake. The United States Agency for International Development (USAID) has granted financial support to develop earthquake risk models for Africa, South East Asia, Central America and the Caribbean. There has also been work in South America (Toquica et al. 2017), Sub-Saharan Africa (Poggi et al. 2017), Portugal (Burton and Silva 2016), Eastern USA (Schmidtlein et al. 2011) and elsewhere. There are therefore clear signs of interest in the topic, but it remains to be seen how successful and influential this interesting and potentially ground-breaking part of GEM's work will turn out to be.

GEM is active in outreach and training; passing on its skills and raising awareness of seismic risk is seen as key to its work. Another key characteristic is that all the software tools that it develops are 'open source' (Silva et al. 2014), to ensure transparency and to enable anyone with the necessary skills to adapt the tools to their needs. Perhaps this transparency explains why the insurance industry, although it has been a major source of GEM's funds, is understood to see the work chiefly as pro bono publico rather directly contributing towards its commercial interests. ${ }^{8}$

\footnotetext{
8 A view expressed to me by an insurance industry professional was that activities like GEM's which aim to reduce seismic risks in less developed countries will eventually open up those countries to insurance
} 
A generic problem of risk quantification is that disasters of the past are not always good predictors of what will happen in the future. This is the 'unknown unknown', 'black swan' problem discussed by Robert Muir Wood (2016). In particular, the complex and rapidly evolving systems which make up today's major urban conurbations may in future respond in quite unexpected ways to the huge challenges posed by a destructive earthquake. An example that Muir Wood gives from the past is that at the turn of the nineteenth to twentieth centuries, the fire hazard in San Francisco was considered almost negligible, due to modern improvements in fire-fighting. What actually happened in 1906 after the great earthquake was that the damage caused by fire exceeded that due to the ground shaking. A more recent example is that the effects of liquefaction on Christchurch from the 2011 earthquakes far exceeded previous expectations. Writing about failure in another kind of highly complex system, the global financial system, a former US financial regulator, Richard Bookstaber (2017), comments on why the sophisticated mathematical models of economists failed to predict the financial crash of 2008:

The point isn't to crank out and act on a number. It is to set up a model to see what light can be shed on a real-world problem, and to see if it can fit a larger, intuitive narrative about what is going on ........ is the plot line a reasonable one?

Of course, we engineers know all about the limitations of the computing tools that we use to model reality. Don't we? However, risk modellers and disaster planners, and the seismic engineers who assist them, need to be well aware that the real world and our idealised models of it are two different things.

\section{Social, political, economic and cultural influences on seismic resilience}

\subsection{The Human Development Index and the impact of earthquakes}

It is well known that earthquakes impact developed and developing countries in different ways. The main cost of damage occurs in the richest countries, but most of the deaths occur in developing ones. Tables 2 and 3 illustrated this for eight specific earthquakes; the tables also show that in the two developing countries listed (Nepal and Haiti), the economic impact was very large, even though the damage figures themselves were relatively small.

To explore whether (as is generally assumed) these conclusions apply more widely, I have attempted in Fig. 3 to show the distribution of global losses and deaths over the past 69 years, and to explore whether there have been any changes during my lifetime. I have looked at deaths and damage worldwide due ground shaking for two almost equal periods: 1948-1982 (the year of my birth to the time I was getting involved in earthquake engineering) and 1983 - present. Note that damage and deaths due to tsunamis are not included. Rather than split the figures by size of economy alone, I have used the UN's Human Development Index (HDI), which also allows for health and education. Details of the calculations are given in "Appendix 3".

Figure 3 confirms that, for both periods, countries with a Very High HDI account for most of the global cost of earthquakes, but only a small proportion of the deaths. The cost,

Footnote 8 continued

markets. Hence such activities may in the very long term also have commercial benefits, as well as fulfilling non-commercial community obligations. 


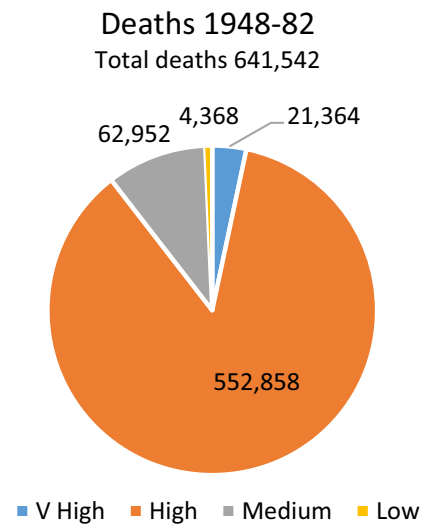

Damage 1948-1982

Total damage US\$122 billion

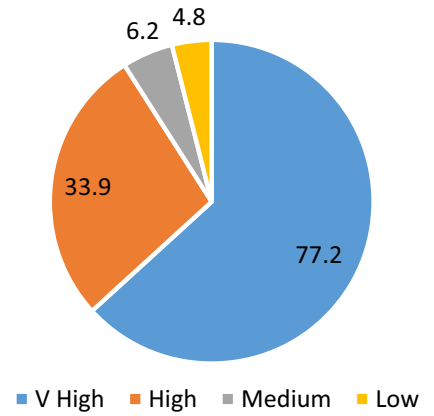

Deaths 1983-2016

Total deaths 610,551

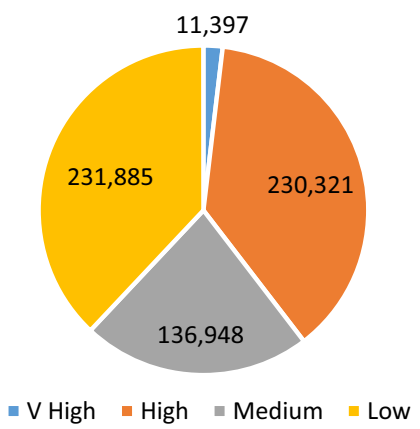

Damage 1983-2016

Total damage US\$364 billion

19.25 .1

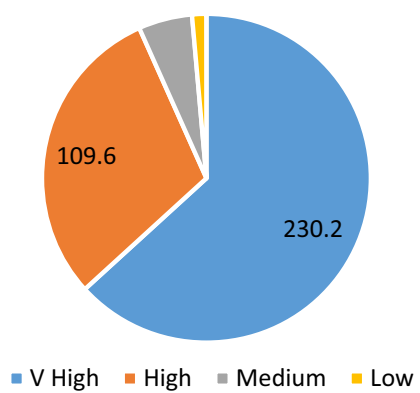

Fig. 3 Deaths and damage (in 1990 US dollars) caused by ground shaking for two periods (1948-1982 and 1983-2016) analysed by HDI. Sources: (1) Deaths and damage due to earthquakes: EM-DAT, CRED, University of Louvain, Belgium (http://www.emdat.be/database). A correction for inflation has been made to adjust the damage to equivalent values in US dollars in 1990 (see "Appendix 3"). (2) HDI statistics: http://hdr.undp.org/en/composite/HDI

after allowing for inflation, can be seen to increase by a factor of about three in the second period, but interestingly the number of lives lost is roughly equal, despite a large increase in the world population. However, the split between the groups has changed a lot. Here is a possible explanation to explain at least some of that change. The richest group-the blue slice- has remained pretty good at protecting its own. Many of the next group down-the orange countries like China and India-have developed enormously and moved up a category since 1948 . Note that I have classified all the countries by their 2016 and not their 1948 rating. In parallel with their move up the HDI table, the orange countries have also got better at protecting their populations from earthquakes, but there is still some way to go. It is the lowest groups where the suffering has increased, with massive movements of population from the country to unsafe megacities like Port-au-Prince in Haïti.

However, the differences in damage and deaths between the various categories could just reflect their relative size; the Very High HDI countries generate most of the world's wealth, but have a much smaller fraction of the world's population. Figure 3 could merely show the unequal distribution of wealth in the world, rather than saying something about 


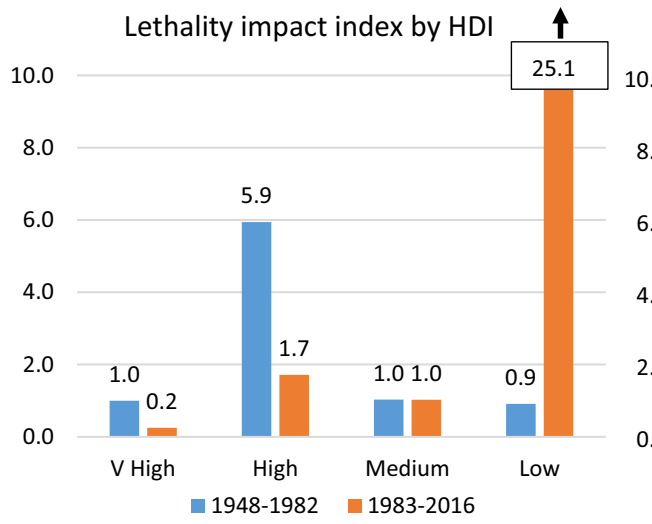

(a)
Economic impact indices

\section{0}

8.0

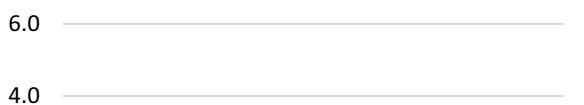

2.5

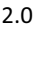

0.0

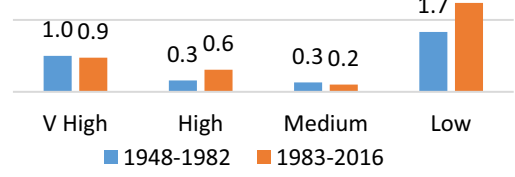

(b)

Fig. 4 Lethality (normalised deaths) and economic (normalized damage) impact indices for the two periods classified by HDI. Sources: (1) Population statistics: https://esa.un.org/unpd/wpp/Download/Standard/ Population/. (2) GDP statistics: The Maddison-Project, http://www.ggdc.net/maddison/maddison-project/ home.htm, 2013 version

earthquakes. To examine this further, I have looked at the number of deaths in each HDI category in relation to their average population in each period (the 'lethality impact index'); this gives a measure of the effectiveness of each group in protecting their populations against death by earthquake. Similarly, I show the total cost of earthquakes in each HDI category in relation to their aggregate GDP during each period; this gives a measure of the economic impact that earthquakes have had (the 'economic impact index'). To make things neater, I have normalised the figures to those for the Very High HDI group of countries during the first period, which are therefore by definition exactly 1 . The results are shown in Fig. 4. Note that for both lethality and economic impact, an index greater than 1 shows a greater (worse) impact than that achieved on average by the Very High category countries during 1948-1982. Lowering of the column bars between periods implies an improving performance.

Statistical analysis of earthquake effects is prone to many pitfalls. The bare data are notoriously unreliable for both losses and number of deaths. For example, there is a factor of three in the range of estimates of deaths tolls from the two most lethal earthquakes of the period 1948-2016, namely Tangshan, China in 1976 and Haïti in 2010, and it is these two earthquakes that cause the two spikes in Fig. 4a; the effect on Fig. 4 of removing Tangshan and Haïti is shown in "Appendix 3"-and it changes things significantly. Loss figures are problematic for developing countries; for example, the monetary value assigned to the loss of adobe houses in rural areas might greatly underestimate their worth to the owners. Also, of course, inflation erodes the value of currencies, but allowing for this is not straightforward. Statistics on the size of populations and economies going back to 1948 are not straightforward to find, either; for one thing, many countries which exist today were not independent states in 1948. However, on the basis of Fig. 4, I believe it is possible to conclude with some confidence that the Very High HDI countries are better able to protect their citizens from death by earthquake than countries in the other categories. And this ability has increased significantly with time. It also seems they have managed to contain the economic impact of earthquakes over time, because although the cost of seismic damage in the Very High HDI countries has increased by a factor of three between the two 
periods, their GDP has kept pace. Since the data involved are reliable and easy to obtain, I am fairly confident of these findings.

By contrast, Fig. 4 suggests that life protection is actually getting worse in the least developed economies. Moreover, earthquakes have a far higher potential for devastating the economies of the least developed countries than developed ones. These findings are less certain, since the underlying data is unreliable and because the (uncertain) death toll and damage from Haït dominates results in the second period (see "Appendix 3", section C6). However, I would be surprised if more careful research yielded significantly different conclusions.

The central thesis of this paper is that the technical contributions that seismic engineers make to improving seismic resilience can be more effective if they are aware of the wider, societal, factors that affect resilience, and Figs. 3 and 4 show how badly an improvement is needed. The following sections explore these wider factors, starting with a definition of resilience.

\subsection{The definition and dimensions of resilience}

Steven Platt et al. (2015) defines resilience against disaster as "the capacity of hazardaffected bodies to resist loss during disaster and to recover after disaster in a specific area in a given period". It is connected with the ability to bounce back after a shock to the system, which may have been unexpected, and to regain a state which is at minimum satisfactory, and ideally as good as or better than before. Note that the losses from which recovery is to be made are not just physical ones but also intangible ones such as community values or personal wellbeing. As the two words resist and recover in Stephen Platt's definition make clear, resilience is a function both of the pre-existing state before the earthquake, and what happens afterwards. The speed with which recovery takes place is clearly central to resilience, but the quality which is achieved is important too. Balancing the need for speed with the achievement of quality creates tensions which are a central issue for the recovery process; Platt and So (2017) discuss how these tensions have been dealt with after recent earthquakes in Chile, Turkey and Japan.

For the purposes of this paper, resilience is taken as a measure of the success in dealing with earthquakes. A key paper by ten US authors (Bruneau et al. 2003), seven of them seismic engineers, proposes that resilience has four distinct dimensions:

- Technical - how physical assets (buildings, transportation systems and so on) stand up to ground shaking.

- Organizational-the capacity of the authorities responsible for critical facilities and post-disaster response to enhance resilience before an earthquake strikes and to respond after it has.

- Social-measures taken to lessen the extent to which communities and governing authorities suffer following an earthquake.

- Economic - the capacity to reduce both direct and indirect economic losses resulting from earthquakes.

This is in line with the systems approach advocated by David Blockley and Patrick Godfrey (2017). The technical work of the seismic engineer must account for the organizational, social and economic systems in which the engineer operates. The next sections discuss some of the dimensions of the systems involved. 


\subsection{Cultural dimensions}

The discussion now moves more deeply into ground unfamiliar to seismic engineers. The emphasis changes from being on the performance of artefacts and its measurement, to an interest in power relationships, cultural attitudes, beliefs. For seismic engineers, this may be destabilizing and unsettling but destabilisation can lead to change, which is surely needed if something is to be done about the rather shocking situation shown in Figs. 3 and 4.

Terry Cannon is a social scientist based at the Institute of Development Studies, University of Sussex. He is one of the editors of a book, 'Cultures and disasters' (Krüger et al. 2015) that is, according to Ian Davis in his foreword to the book, "the long awaited, definitive book that explores the complexities of culture and disaster risk". The editors unashamedly state that "culture is 'messy' and this adds to the 'messiness' already inherent in the context of disasters and disaster risk reduction". The editors also make the bold claim that "culture influences risk in so many different ways....... [it] has an (often hidden) power that enables, or hinders, people and populations to deal with hazards appropriately".

In his contribution to 'Cultures and disasters', Terry Cannon (2015) presents a fascinating representation (Fig. 5) of the complex and interlocking components that contribute to the ability to deal with disasters. The bottom three components of Fig. 5 relate to individuals and single households, while the top two components concern the organisations at village, regional, national or international level which impinge on the households. Terry Cannon gives an extended discussion of the five components he identifies, and how they interact in the context of a disaster, which I will not attempt to reproduce in any detail. However, an understanding of the relationships between the various levels gives insights into how earthquakes are dealt with. Do the elite at levels 4 and 5 view those at the lower

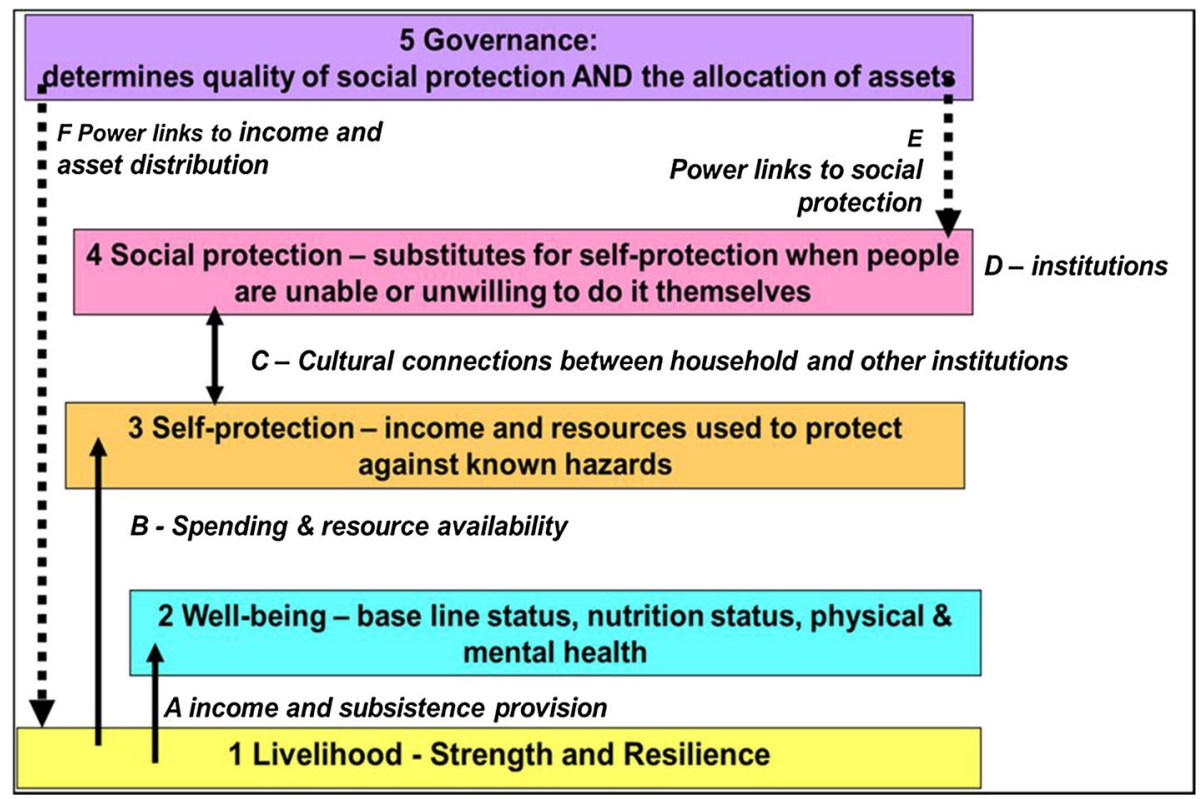

Fig. 5 The five components of vulnerability and their linkages—after Fig. 3 in Cannon (2015) 
levels as lazy, stupid and incompetent or perhaps as helpless victims? Or maybe they are viewed as criminals, whose tendency to looting and anarchy must be firmly suppressed? To what extent does the local community at district or village level have the will and ability to self-organise, independently of help from higher levels? Do individuals become passive and traumatised as a result of a disaster, or do they respond actively, using their own resources? Rebecca Solnit (2009), in her book 'A paradise built in hell', suggests that the ability and willingness to act of those affected by disasters is generally high, and she gives many examples of communities that organise themselves effectively before help arrives from outside. Exactly the same point, with many supporting references, is made by Twigg and Mosel (2017).

A prime example of the effectiveness of community action relates to search and rescue efforts after an earthquake. There is plenty of evidence (for example De Bruyker et al. 1983; Olsen and Olsen 1987; Noji et al. 1993; Iwasaki 2000) that the great majority of those rescued from collapsed buildings are saved by their neighbours in the first few hours after an earthquake; international search and rescue teams are rather ineffective in rescuing lives, because they arrive (inevitably) too late to find many survivors (Roberts 2010).

These relationships of power have a crucial influence on the balance between 'topdown' and 'bottom-up' response to a disaster, a topic that Stephen Platt (2017) discusses for ten recent earthquakes. 'Top-down' measures taken by the authorities should make for the greatest speed of response, and help ensure quality and uniformity. However, they may result in outcomes that the recipients do not want-replacement housing that is either not suited to local needs or is in the wrong place, for example, or demolition of unsafe heritage buildings when the locals would much rather devote resources to restoring them. This can be overcome by a 'bottom-up' response that embeds the local community in the decisionmaking process, but the consultation this involves inevitably slows things down. Whether the right balance is achieved between these two types of response (the 'sweet spot, in Mary Comerio's (2013) phrase) must surely depend to a large extent on Terry Cannon's power relationships, shown in Fig. 5.

Terry Cannon has another challenge that seismic engineers should take note of. Are the aid organisations, which engineers might be working for and helping to run, too wedded to a particular goal, such as improving seismic resilience? Might they be guided by the conditions attached to their funding to pursue one type of agenda rather than consider the range of needs of the recipients? Terry Cannon (2015) asks whether aid organisations might be bound by the 'law of the hammer':

someone who only has a hammer perceives every problem as being a nail. The culture of most DRR [disaster risk reduction] organisations is to believe that the serious hazards people face are the most important problem, and that people must share this priority and divert from dealing with daily needs and risks, leading to a mismatch of priorities and goals that hampers the effectiveness of disaster risk reduction.

An interesting example of culture affecting outcomes is given by Mary Comerio (2013). She was involved in housing reconstruction following the 2010 Maule earthquake in Chile, and was impressed by how well it worked; there was excellent collaboration between government and communities, and the 'top-down/bottom-up' balance hit the 'sweet spot'. Everywhere, that is, except in the city of Talca, where the programme faltered. People there are much more suspicious of government than elsewhere in Chile, and have a tendency towards activities they would prefer the authorities not to know about. This view 
of Talca's independence was not just those of an expatriate; it is well known, one of my Chilean interviewees told me, that the Talcans consider there to be just three great cities in the world-London, Paris and Talca.

I finish this section with another example of how cultural issues can affect engineers very directly. Stephen Platt, in EEFIT's (2013) follow up report on the Tohuku earthquake and tsunami, gives the following evaluation.

In the present reconstruction, with its heavy emphasis on building tsunami defence structures, there is little sign that social science had informed engineering decision making. On the contrary, there is a clear indication that risk aversion drives the process of building ever larger structures against tsunami inundation.

\subsection{Political dimensions}

The political dimension to dealing with earthquakes was very clear in all four places I visited on the study tour (Fig. 1); to illustrate this, I now give four snapshots of how this appeared to be.

(a) In Nepal, the many years of Maoist insurgence was a recent and still deeply painful memory, and some of the consequences of that were discussed in Sect. 2.2. One that had not occurred to me until pointed out by one of my interviewees was that any organisation, including earthquake engineering ones like NSET would be wary against entryism - the risk that Maoists would take them over for their own political ends - and that would tend to make them less open than a society like SECED.

(b) Chile had emerged less recently than Nepal from a traumatic era of civil strife, but the market reforms and deregulation of the Pinochet era were still in place. Previously, engineers had their own professional body which licensed them and also fixed professional fees. "Pinochet stopped all that", one of my interviewees in Santiago told me; in the UK, we know that similar measures in Thatcherite Britain had a profound effect on our industry. "But didn't these reforms lead to the prosperity so obvious in central Santiago?" I asked, noting that Chile is now in the Very High category of Human Development Index. The reply to my question came with great vehemence: "nothing justified the terrible human rights abuses of that time".

(c) The political tensions following the Christchurch earthquake were very evident, too; Sir Robert Parker, mayor of Christchurch at the time of the earthquakes, told me:

Criticism of the way things went in Christchurch was misguided, because in many ways they went very well - it was a huge success. But Central Government felt it needed to impose solutions. There was an attitude of 'we know best'; perhaps this was a legacy from being part of the British Empire. My advice is - don't create a [central government controlled] Canterbury Earthquake Reconstruction Authority, don't have a minister 'in charge of the earthquake', put your trust in locally elected officials and politicians." I would suggest a minister 'supporting the local earthquake recovery' would be a better way to empower the community and bring Government expertise to bear.'

(d) Politics in California (and the rest of the USA) is profoundly affected by the principle of the Founding Fathers to devolve as much as possible to the most local

\footnotetext{
9 This is a paraphrase of Sir Robert Parker's actual words.
} 
level, a form of 'subsidiarity'. California has 450 jurisdictions, all of which are separately responsible for setting building regulations. Many of those jurisdictions are near bankruptcy, and this clearly affects their appetite to spend money preparing for the next great Californian earthquake.

Rebecca Solnit (2009), with a background in journalism, has many examples of the political dimension to disasters, and her book has a chapter called 'Losing the Mandate of Heaven'. This refers to an ancient Chinese concept; the emperor will lose the mandate if he mismanages the Middle Kingdom. Mismanaged response to the 1976 Tangshan earthquake, she suggests, was the tipping point which contributed to regime change in China and Deng's sweeping economic reforms. Other links she makes are between the 1972 Managua earthquake and the fall of the Somoza dictatorship in Nicaragua, the 1985 Mexico City earthquake and the ending of rule by the PRI, (for 80 years the governing party in Mexico) and (from an earlier era) the Lisbon earthquake of 1755 and the major reforms that followed it. Rebecca Solnit writes of the Lisbon event:

Pombal, one of the king's chief ministers, seized power as the King and his court moved to tents outside the city. He used that power to modernize Lisbon, update its building codes, and evict the Jesuits.

Seismic engineers, I suggest, should be aware of the profound influence that politics can have on their work.

\subsection{The international dimension and the role of the United Nations}

UN based efforts to promote an international approach to disaster risk reduction date back to the Eighth World Conference on Earthquake Engineering, which took place in San Francisco in 1984. At this conference, the eminent seismologist Frank Press (1984) proposed that the 1990's should be designated by the UN as the International Decade for Natural Hazard (later Disaster) Reduction (IDNDR). In his Mallet-Milne lecture of 1989 entitled 'Coping with natural hazards', George Housner (1989), another very eminent earthquake engineer from the United States, reported how the UN had adopted the proposal, requesting every member nation to help implement it. The IDNDR culminated in the Yokohama Accord and was followed by further UN initiatives: the Hyogo Framework and, most recently, the Sendai Framework (UNISDR 2015). This latest initiative defines a strategy for the reduction of both manmade and natural hazards, including, of course, earthquakes. The strategy sets seven global targets for disaster risk reduction, to be achieved by 2030; they are reproduced in "Appendix 4". The targets concern a reduction in the deaths and human impact of disasters, a reduction in infrastructure and wider economic losses due to disasters, an increase in the number of countries which have prepared national and local risk reduction strategies and improving the reach of early warning systems and disaster risk information.

What can engineers contribute to the Sendai Framework? Its scope is very broad, covering many aspects of disaster risk reduction beyond those normally considered by engineers, and being largely directed at the government departments of the 193 countries which signed the Framework agreement. The Framework document notes that "there has to be a broader and a more people-centred preventive approach to disaster risk.", and these 'soft', people-centred issues are everywhere emphasised. Thus, stakeholders whose interests must be firmly borne in mind in the design and implementation of policies are listed as including "women, children and youth, persons with disabilities, poor people, 
migrants, indigenous peoples, volunteers, the community of practitioners and older persons". Success in achieving its goals of disaster risk reduction requires "....the implementation of integrated and inclusive economic, structural, legal, social, health, cultural, educational, environmental, technological, political and institutional measures....". This is a long list of different factors, in which that relating to engineering comes near the end. Housner's Mallet Milne lecture, which sets out a framework for the earlier IDNDR, is in sharp contrast; certainly, it recognised that activities other than technical ones would be needed to achieve the IDNDR's goals, citing the importance of public awareness activities, studies in economics, studying culturally based reactions to disasters, and the involvement of planners and financiers. But these are essentially passing references, and there is little doubt that Housner considered the engineer's role as pivotal to disaster risk reduction.

It is not clear whether the community of practitioners referred to by the Sendai Framework in the list of stakeholders quoted above includes earthquake engineers, but one would hope this is the case. The Framework strategy certainly refers to the need for technical and scientific measures to reduce risk; it recognises that "a multi hazard approach is needed, with science-based and traditional approaches both having roles to play" which, while hardly a ringing endorsement of the crucial role that engineers might play in reducing the consequences of natural hazards, at least implies they could make a contribution. However, the role of engineers is not much emphasised or discussed, and the term 'engineer' does not appear once in the Framework's strategy document. Is this because in a broad strategy document, the sordid details of how to implement policies are not appropriate ("leave it to the engineers, they'll do the necessary if we tell them what's required")? Or is it because policy makers meeting in a grand hotel in Sendai are out of touch with the realities of life in the field, have little idea that engineers might play a role in disaster risk reduction and, as is the case for most of us engineers, are too absorbed in the importance of their own field to recognise the contribution of others? Jo da Silva (2012) has written:

At a strategic level, engineers are notably absent amongst the staff of key decision makers (the World Bank, the UN, bi-lateral donors, governments etc.). Nor do these organisations typically engage experienced engineers or engineering firms as consultants in the early stages of recovery and reconstruction, when their experience is most needed in order to prioritise reinstatement of critical infrastructure, and help develop a road-map for recovery. In the event of a pandemic or a terrorist bomb attack with numerous human casualties, failure to consult medical professionals would be unthinkable. It therefore seems absurd that engineers are not engaged in disasters where there has been considerable loss of infrastructure and thus basic services, and particularly so in an urban context.

Comments about the failure to understand the essential contribution that engineers make to disaster relief are not new; they date back at least to the foundation in 1980 of RedR, an organisation which facilitates involvement by engineers in disaster response. Attitudes are changing; engineers are now widely understood to be indispensable in the immediate aftermath of a disaster, and their involvement in preparedness is also becoming more recognised. A good example is the 100 Resilient Cities Initiative ${ }^{10}$ pioneered by the Rockefeller Foundation, which uses the City Resilience Framework developed by the engineering consultancy Arup to develop city resilience strategies and action plans. The Framework recognises the critical role of infrastructure (and ecosystems) in protecting

${ }^{10}$ For further details, see http://www.100resilientcities.org/. 
people and assets, providing essential services, and enabling the flow of goods, services and knowledge. As another example, the report on engineering standards cited earlier (Mouiller and Krimgold 2015) fully recognises the engagement of engineers in the wider disaster preparedness effort.

The absence of engineering content in the UN's Sendai framework and its forerunners is by contrast perhaps inevitable. John Rees of the British Geological Survey, who has had close involvement in these UN initiatives, told me:

Many parties at Sendai sensed that the main gap in delivery of disaster risk reduction is not going to be filled by improved engineering or science, but by better application of what already exists in these fields-an implementation agenda which largely comes down to cultural, governance and political factors.

The UN frameworks for disaster risk reduction were never intended to act on a detailed, executive level and inevitably blandness in objectives and methods characterises their documents, otherwise ratification by all UN countries might not have been possible. With a budget of only \$30million and a global remit, the UN's International Strategy for Disaster Reduction (UNISDR) is primarily a campaigning organisation that cannot deal in specific measures.

Perhaps one important contribution by the earthquake engineering community to Sendai would be to help measure as transparently and accurately as possible whether or not its objectives are met. For earthquakes at least, the 25 year span set by Sendai for the target reductions in mortality rates and economic losses is unlikely to be long enough to give a statistically significant result; the occurrence or absence of an event like the Haiti earthquake, with its huge death toll, could completely change the figures. Instead, by focussing on modelling and quantifying the effect of changes in resilience with tools such as those developed by GEM (see Sect. 6.4), potential reductions in risk-and hence real changes rather statistical flukes - should become apparent. It would be a case of engineers using their 'habits of mind' to support the wider disaster risk reduction community. There was no great confidence among those I talked to that Sendai will be any more successful in achieving its objectives than its predecessors were, but the measurement and publicising of changes to disaster resilience would still be valuable, even if it showed that targets were not being met.

UN initiatives may not by themselves be able to create the solutions to 'dealing with earthquakes', in a way that they have for medical threats such as AIDS and Ebola, but at least they can help put disaster risk reduction on the political agenda. And it is to be hoped that engineers will play a full part in developing the disaster risk reduction strategies that the Sendai framework calls upon national governments and local authorities to develop.

\subsection{Economic dimensions}

While seismic engineers might be inclined to question whether their work is influenced by culture or politics, they can hardly doubt that money is important. When I asked what the key factors were on the way Nepal coped with its earthquakes in 2015, an engineer working in Kathmandu said immediately "It's all down to money". A distinguished Californian seismic engineer told me that $95 \%$ of the design projects he had worked on during his long career in consultancy had been dominated by economic considerations; factors such as improving earthquake performance were of little interest to most clients and meeting the legal requirements for seismic resistance at minimum cost was the prime concern. With the continuing developments in, and awareness of, performance based 
design, that appears to be changing, but the change is gradual; my Californian contact told me that it is only owners with a clear understanding of the need for continued use of their buildings (e.g. Emergency Operations Centers, Corporate computer centres, etc.) who are incorporating improved performance into their buildings.

Of course, the rich economies are pretty good at protecting their citizens from dying in earthquakes, as Fig. 4a showed, so perhaps the best way to enable the world to deal with earthquakes is simply to lift all economies out of poverty and into the Very High HDI category. Leaving aside the question of how that might be done, and how engineers could assist, there is much to be said for this view. Before an earthquake, meeting everyday basic needs is likely to seen in the poorest countries as much more important than preparing for an earthquake which might be a generation or more away. A low economic base makes it much harder to train — and retain — an educated elite and (just as important) a skilled workforce that can construct resilient infrastructure. After an earthquake has struck, the economic impact on poor communities may be so great (Fig. 4b) that it takes them many years to recover. Figure 2 in Sect. 6 suggests that insurance money will not be much help for the poorer countries, either.

However, the link between economic development and seismic resilience is much more complex than being just a question of money. Urbanisation and globalisation have been two drivers of economic development, and both can have negative impacts on resilience. People moving from rural areas to cities often end up living in the sort of poorly built concrete buildings that proved so lethal in the Turkish earthquakes of 1999 (EEFIT 2003). After an earthquake, they may become more vulnerable to the loss of services, which the hardier country dwellers have always lived without. Those left in the country suffer too; urbanisation and globalisation may lead to more cash coming into rural areas, as those that have left send money they have earnt back home, but it also leads to a loss of vital construction skills. The megacities that have sprung up so rapidly will take time to develop the municipal services and regulatory capacity, the skilled construction workers and the organisations that lead to resilient infrastructure. One of my interviewees, Svetlana Brzev who is a leading expert on the seismic use of masonry, pointed out that the masonry industries in countries like Canada or Chile collaborate to ensure good standards; this just does not happen at the moment in India and Nepal, and this means brick buildings are less resilient. The construction industries in rapidly growing cities in the developing world are notoriously corrupt, and two previous Mallet-Milne lecturers, Ambraseys and Bilham (2011), have explored how this is linked to high death tolls in earthquakes.

If a conclusion is needed, it is that while seismic engineers need to be aware of the economic dimensions of the places they operate in, the issues and systems involved are too complex to be described purely in terms of money, as I have done in my figures. I want to finish this section with Anthony Oliver-Smith's (2015) interpretation of the root economic causes of the catastrophe that struck Port-au-Prince in 2010. You may not agree with all of it, but it paints a story of unintended consequences due to complex power relationships that is well worth pondering on.

Oliver-Smith lays much of the blame for Haiiti's disaster on the neoliberal economics of the late twentieth century. At the end of the twentieth century, the country was heavily in debt as a result of the ruinous rein of 'Baby Doc Duvalier'. Its powerful neighbour, the USA, then ordered the slaughter of all of Haiti's pigs, to limit the spread of the African flu swine virus. This left the rural population even more impoverished, so they cut down more and more trees to produce charcoal, leading to almost complete deforestation of the island. The construction of large industrial agro-processing facilities, encouraged by the USA, made it even harder for small farmers to survive, and tariff reductions imposed by the 
International Monetary Fund on Haïti's staple diet of rice made local production uneconomic. So the peasants moved to the cities, where demand for jobs quickly outstripped supply; the political turmoil of the Duvalier and post-Duvalier years were not conducive to job creation or provision of social services. The peasants ended up in "festering slums and hillside shantytowns with few services of any sort". It was a disaster waiting to happen.

\subsection{Dimensions of religion and belief}

Religion is often referred to in negative terms as an obstacle to dealing successfully with earthquakes, because it is seen as being associated with a fatalistic attitude. Thus if disasters are God's punishment for wickedness, then there is little point in trying to protect oneself; it is not possible to avoid God's will. There are certainly examples of people from all the major religions having these attitudes. But religion and personal belief can have a positive impact too. The International Federation of Red Cross and Red Crescent Societies (IFRC's) annual report (IFRC 2014) on world disasters has a chapter on religion and beliefs which contains this nicely balanced summary of what their influence can be:

There are at least six reasons why beliefs are relevant to disaster risk reduction. The positive ones are that beliefs:

- help people cope with the immediate impacts and longer-term consequences of a disaster and are an important psychological and social element in recovery

- can provide a reserve of social capital that can be tapped to facilitate recovery, including support, information and resource sharing such as donations

- can provide a platform, framework and social grouping that can be useful for educating about risk reduction.

Those that are invariably less helpful involve beliefs that:

- can be an obstacle for building back differently, relocating people or making other changes to livelihoods to help reduce exposure or sensitivity to future hazards

- contribute to creating the vulnerability that can convert hazards into disaster

- can create an alternative reality that makes it difficult to educate about risk reduction.

A rather moving example of an interface between the work of seismic engineers and religion was given in a paper presented to the 16th World Conference on Earthquake Engineering. The authors, Sebastien Penmellen Boret, an anthropologist, and Akihiro Shibayama (2017), an engineer, discuss the many memorials built to victims of the 2011 Japanese tsunami. They argued against the notion that the memorials are useless piles of stone that will be forgotten and ignored by future generations, which they do nothing to protect. On the contrary, they say their research shows that monuments are valuable not just in themselves but for the storytelling, commemorative ceremonies, archiving and disaster education that they are associated with. Robert Muir Wood (2016) gives another example of a memorial, one built in response to public pressure by the authorities in a firmly secular society. He describes a black granite wall, $400 \mathrm{~m}$ long, on which is inscribed the names of 30,000 victims of the 2008 Wenchuan earthquake in China. This is an engineering artefact with a non-utilitarian role to play, but one which engineers should understand is important. 


\subsection{The press and other media}

The media, and their reporting of earthquakes, impinge in a number of ways on the work of seismic engineers. For example, we are in demand after an earthquake as 'experts' to provide comments on what has happened, which is flattering, but Fig. 6, which I discuss later, shows a less comfortable interaction. Should we just accept media attention as a fact of life, and get on with our work, or is there more to be said?

Generalisations are dangerous, because the press and media are formed from such a wide range of different components, each with its own audience. That audience may be influenced by reports in the media that they read or look at, but their interests will also dictate the type of content that the media make available. Broadsheet and tabloid newspapers may present different views of the same event, rich countries in the west will not have the same interests as developing nations, television will add its own particular slant because of the way it presents news and opinion. The degree and manner to which authorities control press and media content will also affect what is published. Internetbased social media add yet another dimension.

These are matters for unpicking by social scientists, not seismic engineers. A paper by Robert Stallings (1990) provides a discussion of some of them, as does the chapter by Kenneth Hewitt in "Cultures and Disasters" (Krüger et al. 2015) and I will not attempt to reproduce the arguments in any detail. There are two points I would like to make, however, one negative and one positive. The first point is that there are widespread imbalances in media reports of earthquakes. The western media reported in detail on the plight of European tourists stranded in beach resorts by the Boxing Day tsunami of 2004 and in the Himalayas by the Nepal earthquakes of 2015. The tourists no doubt represented the human story of most interest to their readers or viewers, but they were a small percentage of the hundreds of thousands of people affected by the earthquakes. That surely is an imbalance,

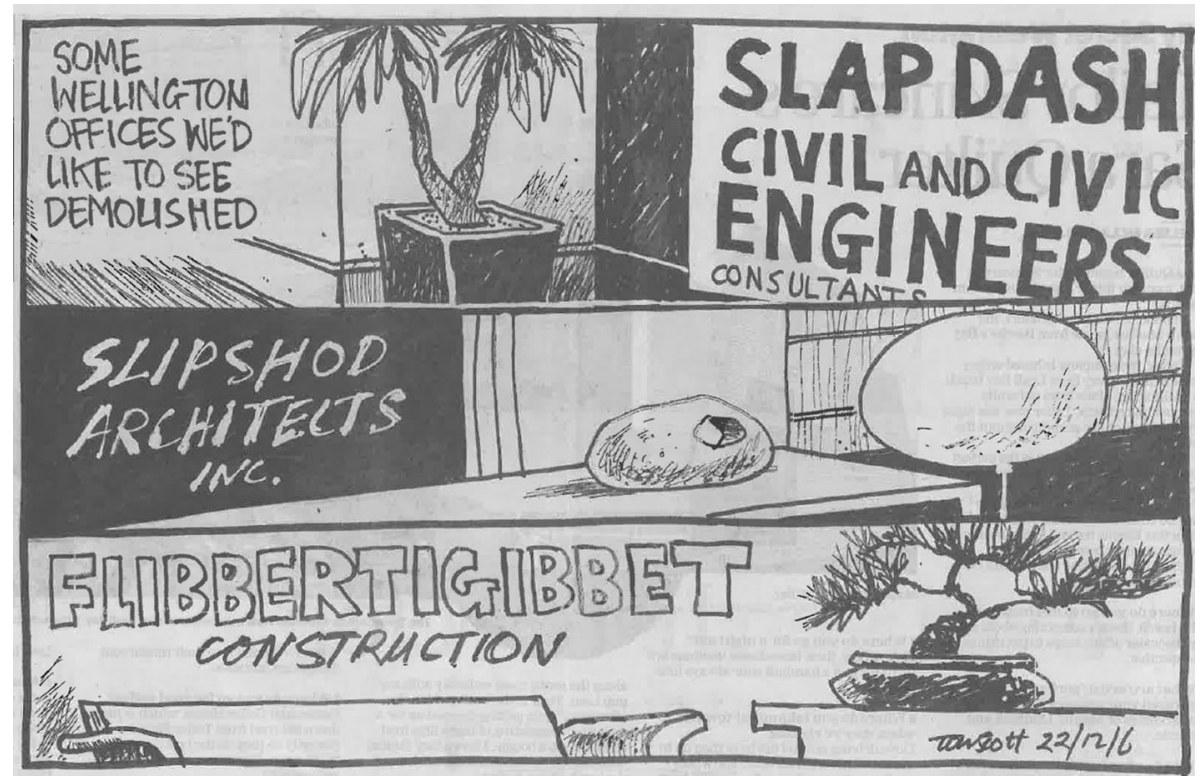

Fig. 6 cartoon by Tom Scott in the Dominion Post 22/12/2016 following damage to some office buildings in Wellington, New Zealand after the 2016 Kaikoura earthquake, which killed two people 
justifiable or otherwise, and one which may have influenced the response in terms of aid or charitable donations by governments and the general public in the West.

Another imbalance is discussed by Robert Muir Wood (2016); the rescue of victims from the rubble of collapsed buildings provides an intensely human story which makes for great television in the West, particularly if international rescue teams emerge as the heroes. These teams are nourished by this oxygen of publicity, and many such appear at the scenes of earthquake devastation. However, as discussed in Sect. 7.3, international rescue teams are rather ineffective. Maybe the skills and resources going into international rescue teams would be better spent elsewhere.

A final, and more disturbing, imbalance in reporting forms an underlying theme of the inspiring book by Rebecca Solnit (2009); it is the assumption in many media reports that looting and anarchy are an inevitable and widespread consequence of damage to infrastructure following a disaster, because of the consequent removal of some of the props to civilisation. Rebecca Solnit is most passionate in her rejection of this assumption, and in her condemnation of the actions it has led to, when she discusses the flooding of New Orleans by Hurricane Katrina in 2005, but she also gives plenty of similar examples related to earthquakes, including the 1906 San Francisco earthquake.

My second point is the positive one that the media have a vital role to play, before and after earthquakes. They provide information, which even though it may not be perfectly balanced, draws rapid attention to events beyond their area of immediate impact, up to a global scale. If seismic engineers are unaware that a major earthquake disaster has occurred, then they cannot bring their skills to bear on it; it is the media which will most likely tell them first. But more than information, they provide analysis. Of course, there may be an overemphasis on finding someone to blame which may well sell newspapers, particularly in areas close to the earthquake, but learning the lessons from disasters is so important, and the media have a vital role to play here. The lessons that the press is most interested in probably will not be technical ones, but organisational and societal ones; that is right and proper. There will also be a need to investigate the issues more carefully and dispassionately than the press usually does, and this is the role of organisations like EEFIT or EERI, or the Canterbury Earthquakes Royal Commission (2012) set up to draw lessons from the devastation in Christchurch. Still, there is no doubt that it is the press that is most likely to move things. A prime example is the opening of Soviet Armenia to western agencies and the western press after the Spitak earthquake of 1988, which gave a much more detailed view of the Soviet Union and its failings than ever before; it has been argued this played a significant part in the breakup of the Union in 1991.

The press sometimes turns its attention directly to seismic engineers. Criticism such as that shown in Fig. 6 may seem to us rather unfair, but surely it is salutary, and the image is much less brutal than the ones that politicians routinely have to put up with. A cartoon in the Turkish press, filled with more anger, showed low rise apartments waiting for the Kocaeli earthquake of 1999 (EEFIT 2003) to turn them into coffins; another showed smart modern high rises in Istanbul disintegrating into rubble under strong shaking. As building professionals, we must surely be willing to share some responsibility for the anger.

A more detailed criticism of our profession appeared in the Nelson Mail of 22nd December 2016, under the headline "'Murky science' of quake engineering":

The head of New Zealand's Property Council has dismissed seismic engineering as a 'murky science', as calls for greater transparency on building reports mount. Property Council chief executive Connal Townsend says members have reported the 
same building assessed by different engineers as both earthquake prone and better than 100 per cent of the new building standards [NBS].

“[Engineer] X might say it's 66 per cent of NBS, but [engineer] Y might say it's 120 [per cent] and someone else might say it was below 33 [per cent]," Townsend said. "We've heard of astonishing differences between engineers. The question is, what's the answer that the landlord wants?"

As someone who has been involved in many seismic assessments of buildings, I have to agree that the criticism has more than a little basis in reality. Part of the response to reports such as this should be to try and explain ourselves better, in this case perhaps setting out some of the reasons why seismic assessments are so difficult, and how they have saved lives and investments in the past; indeed, the New Zealand seismic community did just that, following press reports about their 'murky science'. But Tom Scott (Fig. 6) and Connal Townsend (quoted above) would rightly be dissatisfied if we restricted our response to finding excuses; we have to admit that there is room for improvement and that we need to find more effective ways of dealing with the problem. Actually, New Zealand has contributed as much as anywhere in the world to that search, but none of us can rest on our laurels. Preventing complacency and goading us to action may be an important function that the press can help us with.

\section{The case for Buddhist seismic engineering}

In this paper, I have examined how the 'murky science' of earthquake engineering interacts with the 'messiness' of wider, cultural issues. Engineers react badly to suggestions that their work is murky, and are uncomfortable when dealing with messiness, and so it is hardly surprising that my paper does not arrive at clear conclusions of the best way to proceed, nor does it provide single answers of how to 'deal with earthquakes'. Let me therefore turn again to Schumacher's book Small is Beautiful (1973), which is the inspiration for my subtitle, 'seismic engineering as if people mattered'. The heart of Schumacher's argument is stated in chapter 4, called 'Buddhist economics'; in it, he argues that the primary goal of economic activity should not be the brutal maximisation of output and consumption, measured purely in terms of money. Rather, he says, the goal should be creative activity and human fulfilmenteconomics as if people mattered. Could there perhaps also be a people-centred Buddhist seismic engineering? Here are some suggestions.

Fred Krüger et al. (2015) and his fellow editors in their introduction to 'Disasters and cultures' say that the priorities of disaster risk reduction should be 'supply driven' not 'demand driven', set to meet the needs of people at risk. In the same volume, Kenneth Hewitt (2015) makes the following pronouncement, which to me has a Buddhist ring to it.

Culturally sensitive approaches to preventive and community safety .... \{ should] focus on people rather than rules, persons at risk rather than 'systems' or 'indicators'; on enhancing relationships rather than 'processing', participation rather than control, shared decision making rather than top-down, enforced compliance; on non-violence rather than coercion, and reconciliation and compensation rather than policing and punishment.

Could these warm words actually influence the way that seismic engineers carry out their work? I believe that there are lessons here for us. One is that we need to acknowledge that the way the general public looks at the world is different from the way used by the profession that we love, and that pays our wages. We need to free ourselves sufficiently to look outside the 


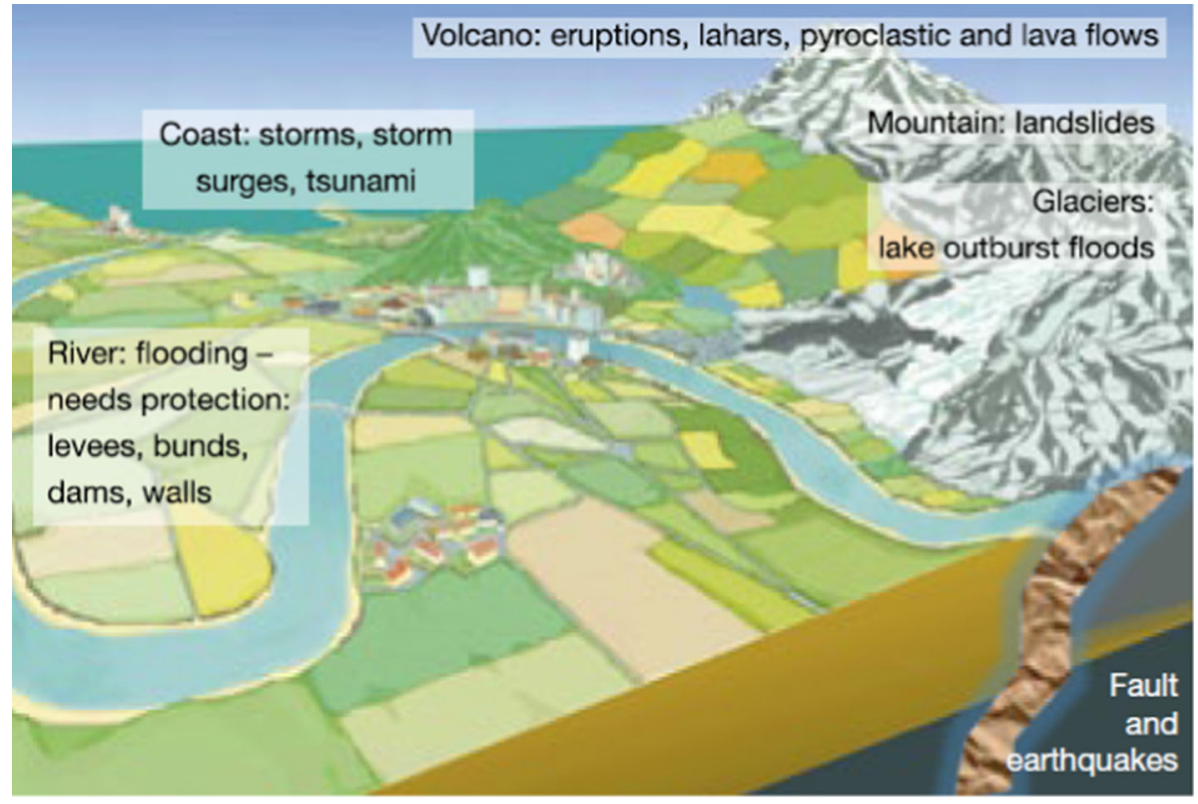

(a)

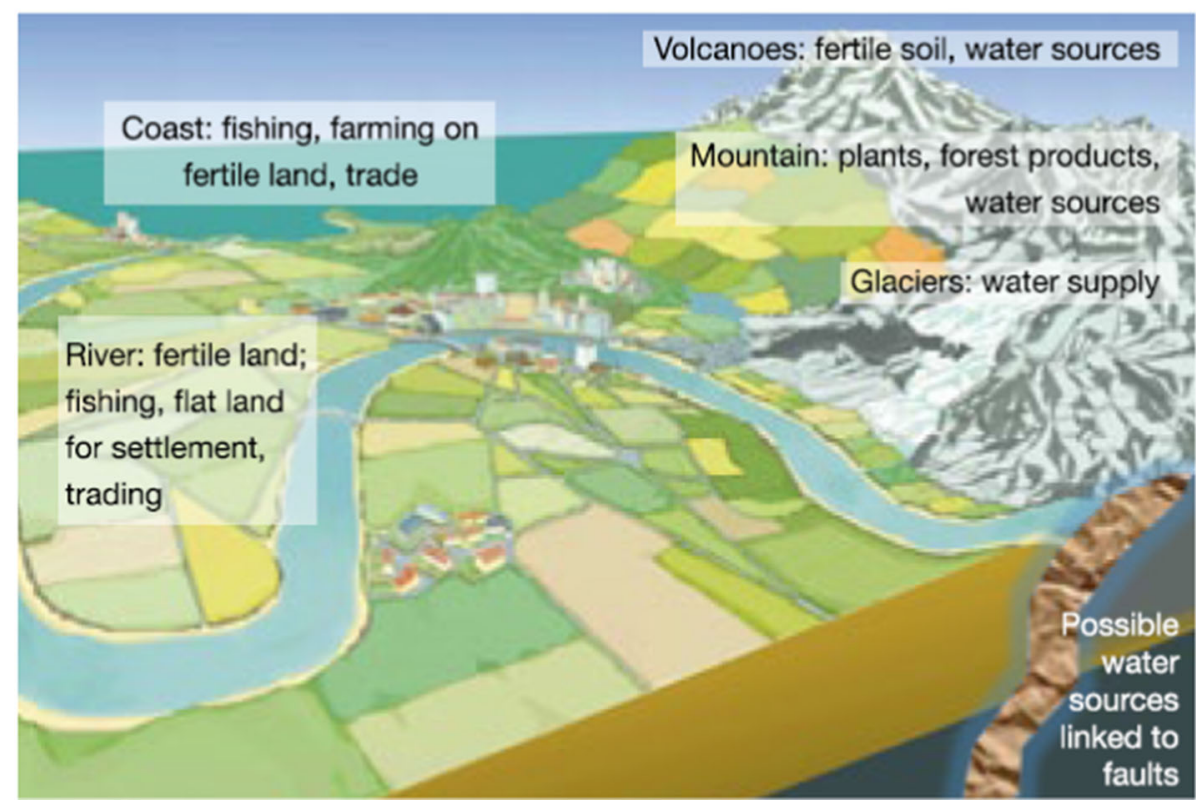

(b)

Fig. 7 Terry Cannon's two views of the same landscape From World Disasters Report: 2014-Focus on culture and risk (IFRC 2014). a The viewpoint of the Disaster Risk Reduction organisation: hazards are obviously the main problem to deal with. b The viewpoint of most people: the landscape is a source of livelihood resources 


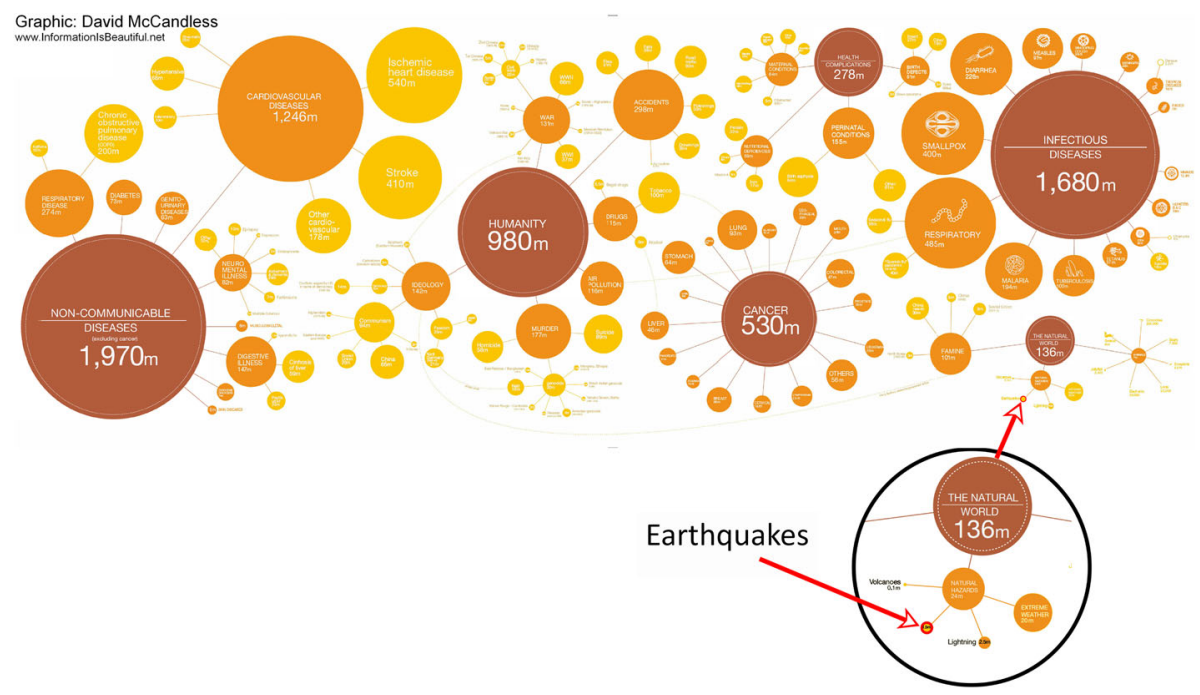

Fig. 8 Total deaths attributable to different causes for the twentieth Century. Source: David McCandless, www.informationisbeautiful.net

bunker of our discipline to the wider world beyond. Figure 7, by Terry Cannon illustrates this point very well. When we look at the landscape, our engineering habit of mind correctly prompts us to identify the various threats-flooding, storms, tsunami, volcanoes, landslides - and earthquakes - that may threaten the people that live there (Fig. 7a). But if we were the ones actually living there, we might see things quite differently, as shown in Fig. 7b; the threats might then morph into vital and benign sources of livelihood. We need to be able to put earthquakes into their context, and appreciate that they are only one of many concerns that face people living in seismic areas. We need to realize that the residents of earthquake country are better placed to rank these concerns than we are, and indeed may have developed effective ways of dealing with them that we could learn from.

In the crude terms of threat to life, a wonderful graphic by David McCandless (Fig. 8) places earthquakes into a global context. The figure classifies the total number of deaths from all causes during the twentieth century; each of the main brown balloons represents one of those causes, and the size of the balloon is proportional to how many deaths that particular cause was associated with. The balloon representing deaths from the 'natural world' (i.e. from natural disasters) is actually the smallest and if you look at the number killed by earthquakes, it is a rather insignificant spot.

David Kelly (2012) makes a similar point for New Zealand:

Since records began in 1843, 483 people are recorded as having died in New Zealand as a result of earthquakes. The vast majority of our earthquake fatalities -447 people - resulted from the two terrible earthquakes in Christchurch in 2011 and Napier in 1931. By comparison, more than twice as many people (1125) died on [New Zealand] roads in the 3 years from 2008-2010.

So here are my suggestions for practising Buddhist seismic engineering, 'as if people mattered': 
- We need to understand the concerns and goals of the people we are working to protect. Earthquake protection may be our principal concern, but others may have different priorities.

- Engineering habits of mind are wonderful for addressing technical problems, but they sometimes get in the way of seeing the bigger picture.

- We should be humble enough to realize that we are not always right, and that people outside our discipline might sometimes have better ideas of how to deal with earthquakes than we do.

- We need to remember the importance of communicating with people outside our professional circle. We do not have to be expert communicators; it is sufficient to be direct and honest. I have already quoted Bob Parker's advice, but it is worth repeating: 'authenticity is more important than communication skills; an authentic voice is humble, honest, compassionate'.

\section{Final reflections: the true nature of engineers}

Finally, I want to make it clear that, while the occasional bit of meditation might do no harm, I do not believe that the solution to dealing with earthquakes is for seismic engineers to adopt the lotus position when sitting at their computers. Shakespeare, not a Buddhist so far as I am aware, advised 'To thine own self be true', and engineers should never lose sight of the need to concentrate on what they are good at and were educated to do: the task of building functional, practical and economic artefacts that meet the needs of society.

Let me give you an inspiring example of where engineers achieved this while fully accounting for the societal context. Duncan Gibb led the team charged with the task of restoring Christchurch's infrastructure after the 2010-2011 earthquakes. He describes this in his Brunel Lecture of 3 years ago (Gibb 2014); it is required reading for Buddhist seismic engineers. Duncan Gibb and his team, when setting up their organisational structure, recognised the importance not only of linking the engineers with government, but also of involving local communities at a grassroots level. Thus 'community engagement', measured by surveys across the city, was one of the key performance indicatorsKPIs - that the team was set. Moreover, engineers, after a hard day's work on site, often found themselves in church halls and elsewhere of evening, explaining what they were doing and getting feedback from the people that lived there. Even so, the quality, cost and timeliness of what was built were at the top of the list of KPIs. Duncan Gibb says that while engineers can be effective social innovators (and in this case they clearly were), first and foremost they are people who make things happen and get things done.

Acknowledgements The funding for the travel expenses which made this paper possible was provided by the following UK based learned societies: Society for Earthquake and Civil Engineering Dynamics (SECED), Earthquake Engineering Field Investigation Team (EEFIT) and the Institution of Civil Engineers' Research and Innovation fund. The lecture based on this paper was delivered by the author at the Institution of Civil Engineers in May 2017 and that event was sponsored by the following commercial organisations based in the UK: Arup, Atkins, CH2M, Jacobs, Risk Management Solutions, AIR Worldwide and Cambridge Architectural Research Ltd. These generous contributions are gratefully acknowledged. The willingness of all those listed in "Appendices 1 and 2" to give me their time and the fruits of their wisdom and experience was remarkable, and is also acknowledged with grateful thanks.

Open Access This article is distributed under the terms of the Creative Commons Attribution 4.0 International License (http://creativecommons.org/licenses/by/4.0/), which permits unrestricted use, distribution, 
and reproduction in any medium, provided you give appropriate credit to the original author(s) and the source, provide a link to the Creative Commons license, and indicate if changes were made.

\section{Appendix 1: People interviewed on the study tours (see Table 2)}

\section{Kathmandu, October 2015}

\section{Chninatsu Endo, UNDP Nepal}

Vivek Rawal, architect and UNDP advisor

Umesh Diwal, Department of Architecture, Tribhuvan University

Sunil Khadka, Architect/planner/co-ordinator with Ministry of Health and Population

James Goodman, structural engineer, John Sanday and Associates

Surendra Bajracharya, structural engineer, John Sanday and Associates

Paul Jaquin, Structural engineer, AECOM London

Rossella Nicolin Structural engineer, AECOM London

Rohit Ranjitkar, Nepal director, Kathmandu Valley Preservation Trust

Bibhuti Raj Pradhan, architect, John Sanday and Associates

John Sanday, architect, John Sanday and Associates

Dr Buland Thapa, Chief Medical Superintendent, National Trauma Centre, Bir hospital Gyanendra Shakyo, Architect, Ministry of Health

Raju Man Manadhar, architect, Ministry of Urban Development and Building Control Jitendra Bothendra, structural engineer, Miyamoto International, New Zealand Dr Gunraj Lohani, Chief of Curative Division, Ministry of Health and Population Amod Dixit, geologist, Nepal National Society for Earthquake Technology

\section{Northern California (Sacramento and San Francisco bay area), August and September 2016}

Richard McCarthy, engineering geologist, California Seismic Safety Commission Randolph Langenbach, architect, ConservationTech Brian Tucker, geologist, GeoHazards International Anne Sanquini, geologist \& disaster scientist, GeoHazards International William Holmes, structural engineer, Rutherford + Chekene Khalid Mosalam, structural engineer, Pacific Earthquake Engineering Center Mike Mieler, structural engineer, UC Berkeley (currently Arup)

Ayse Hortacsu, seismic risk engineer, Applied Technology Council

\section{Wellington and Christchurch, New Zealand, September 2016}

Richard Sharpe, structural engineer, Beca

Mike Stannard, structural engineer, Ministry of Business, Innovation and Employment Win Clarke, structural engineer

Rob Jury, structural engineer, Beca

Richard Fenwick, structural engineer, University of Canterbury

Tim Sullivan, structural engineer, University of Canterbury

Rajesh Dhakal, structural engineer, University of Canterbury 
Roger Sutton, electrical engineer, former CEO of the Canterbury Earthquake Recovery Authority

Duncan Gibb, Civil Engineer, Fulton Hogan

Andrew King, engineering risk specialist, Institute of Geological and Nuclear Sciences

Robert Finch, engineer, Quake Centre, University of Canterbury

Jitendra Bothendra, structural engineer, Miyamoto International, New Zealand

Sir Robert (Bob) Parker, businessman, formerly mayor of Christchurch and broadcaster

\section{Santiago de Chile, January 2017}

Mary Comerio, professor of architecture, UC Berkeley

Fred Krimgold, architect, Virginia Tech

Svetlana Brzev, structural engineer, British Columbia Institute of Technology

Andrew Charleson, structural engineer, Victoria University of Wellington

Roberto Gesche, geotechnical engineer, University of Chile

Hernan Santa-Maria, professor of structural engineering, Universidad Catolica de Chile Tomas Zegard, structural engineer, Universidad Catolica de Chile

Catarina Yepes Estrada, GEM

Maria Ofelia Moroni, structural engineering professor, University of Chile

Ramon Verdugo, geotechnical engineer, principal of CMGI (geotechnical consultancy) Santiago

Felipe Ochoa, geotechnical engineer, University of Chile

\section{Appendix 2: Other people interviewed or consulted by email}

David Blockley, structural engineer, University of Bristol

John Twigg, Department of Civil, Environmental and Geomatic Engineering, University College London

Robin Spence, structural engineer, CAR Ltd and University of Cambridge

Stephen Platt, social scientist and planner, CAR Ltd and University of Nottingham

Anselm Smolka, senior advisor to Global Earthquake Model (GEM) and formerly Munich Re, Germany

Polat Gulkan, structural engineer, Middle East Technical University, Ankara

Jun Kanda, structural engineer, Department of Architecture, CST, Nihon University

Cinthia Rojas, journalist and Associate at the Universidad Catolica del Norte, Antofagasta

Martin Williams, structural engineer, University of Oxford

Anthony Blakeborough, structural engineer, University of Oxford

Vitor Silva, seismic hazard modeller, GEM, Pavia

Terry Cannon, social scientist, Institute of Development Studies, University of Sussex Tom Tobin, geotechnical engineer, California

Jo da Silva, structural engineer, Arup, London

Scott Steedman, geotechnical engineer, BSI, London

John Rees, geologist, BGS and NERC, Keyworth UK

Jan Eichner, loss modeler, Munich Reinsurance Company, Munich

Stephen Broadberry, economist, University of Oxford

David Alexander, professor of risk and disaster reduction, University College London Ilan Kelman, disaster risk specialist, University College London 


\section{Appendix 3: Basis of calculations shown in Figs. 3 and 4}

\section{Introduction}

Figure 3 attempts to show global deaths and damage due to earthquakes worldwide for two periods (1948-1982 and 1983-2016), classified by the Human Development Index (HDI) of the countries in which the earthquakes occurred. Figure 4 normalizes these data by the population and economic output of the countries, as explained more fully below; it therefore attempts to show earthquake impact as a function of HDI. There are many statistical and conceptual difficulties associated with calculating the data for both figures, as discussed in Sect. 7.1 and this appendix, and I accept that the results presented here are far from definitive. I hope that others may take on the challenge to produce more reliable results. On application to me by email (edmund@booth-seismic.co.uk) I will send a copy of the spreadsheet used to calculate the figures.

I am grateful to the help given by Robin Malloy of the Department of Engineering Sciences, University of Oxford, in producing Figs. 3 and 4.

\section{Sources of data}

The figures for damage and death toll have been taken from the University of Louvain's EM-DAT database (http://www.emdat.be/database). The HDI figures are taken from the United Nations Development Programme website (http://hdr.undp.org/en/composite/HDI). The results are presented as the pie charts of Fig. 3.

The population data are taken from the United Nations Department of Economic and Social Affairs website (https://esa.un.org/unpd/wpp/Download/Standard/Population/). The average population for each country during the period 1948-1982 has been taken as the sum of the population figures for each of the 35 years 1948-1982 divided by 35, and similarly for the period 1983-2016.

The United Nations publishes data for economic output, but the data series does not extend back to 1948. Therefore, data from the Maddison Project has been used (The Maddison-Project, http://www.ggdc.net/maddison/maddison-project/home.htm, 2013 version). For the period 1948-1982, the sum of the Gross Domestic Product (GDP) figures given for each country for each of those years have been summed, to provide a measure of total economic output for the period. A similar calculation has been done for the period 1983-2016. The figures are given in 1990 US dollars.

\section{Normalization calculations}

The normalized data shown in Fig. 4a for lethality impact have been calculated as follows. For the period 1948-1982, the total number of deaths in each HDI category in Fig. 3 has been divided by the average population for that period summed over all countries in the relevant HDI category-the raw lethality impact. The result for each HDI category has then been divided by the raw population impact for the Very High HDI countries; this means that the resulting lethality impact factor is by definition 1.0 for Very High HDI countries. For other HDI categories, a lethality impact factor exceeding 1 means that on average the countries in that category were underperforming the Very High category countries. For the period 1983-2016, a similar calculation has been performed except for the last step; the raw lethality impact factors have been divided by the raw factor for Very 
High HDI countries for the period 1948-1982-i.e. the same number as before. For all categories, therefore, a number greater than one implies a performance worse that the Very High HDI countries achieved in 1948-1982. Note that if the column height for each category in Fig. 4 reduces in the second period, it suggests an improving performance.

Figure $4 \mathrm{~b}$ for economic impact has been calculated in an exactly analogous way, by dividing the total economic loss for each category in each period by the aggregate economic output for that category to calculate the raw economic impact, and then by the raw impact for Very High HDI countries in the first period to get the economic impact index.

Unfortunately, the EM-DAT damage figures are given in historic prices-in other words, they relate to prices obtaining at the time of each earthquake, and therefore they do not allow for inflation. This means that loss figures between the two periods are not comparable; a given amount of damage in the first period is expressed with a numerically smaller number than if it had occurred in the second period, because of inflation between the two periods. $\$ 1000$ in 1990 would have bought more than $\$ 1000$ in the period 1948-1982; on average, it would have been worth $\$ 4055$ in 1990 dollars, over four times as much. Similarly, on average $\$ 1000$ in the period 1983-2016 would have only bought $\$ 809$ worth of goods in 1990 dollars. An adjustment for inflation has therefore been made to the EM-DAT figures as follows. The total loss for all HDI categories in each year in the period 1948-2016 has been converted from historic prices into 1990 US dollars. This was done by calculating the loss for each of the years 1948-2016 in each HDI category, as given by the EM-DAT database, and then multiplying by the appropriate inflation factor, calculated from http://www.usinflationcalculator.com/inflation/historical-inflation-rates/. Having calculated the inflation adjusted losses for each category for each of the years 1948-2016, the inflation adjusted total for the two periods followed.

\section{Conceptual difficulties with the normalization calculation}

Many regions of the world with large populations and economies did not suffer damaging earthquakes during either or both periods being considered. Note that some of these regions (such as Port-au-Prince during the period 1948-1983) are in areas of high seismicity. To include the population and economic data for these regions in the normalization calculation described above would clearly result in misleading results.

The measures taken to allow for this when producing Fig. 4 are admittedly extremely crude. They are as follows.

1. Countries for which the University of Louvain's data base show neither deaths not damage for one of the periods have been excluded from the calculations for that period.

2. For each period, countries where both the number of deaths was less than $0.0003 \%$ of the average population, and was less than $0.3 \%$ of the average annual economic output were also excluded. However, the (relatively very small) numbers for death and damage in these countries have been retained in the totals.

3. All the figures for death and damage given by the University of Louvain's data base for the USA have been attributed as occurring solely in California. The population and economic activity figures used in the normalization process have been estimates of those for California alone, and not the rest of the USA.

4. Large populations, generating significant economic activity, lived in areas of India and China in which no significantly damaging earthquakes occurred in one or both of the 
two periods, but no allowance was made for this; the population and economic activity figures are taken for the whole of China and India.

\section{Statistical difficulties}

1. Many countries which are now independent nations did not exist as such in 1948. Notable examples relevant to this exercise are the countries formerly part of Yugoslavia and the USSR. Data for the USSR from the Louvain database have been classified as being for High HDI countries in the period 1948-1992. Subsequently, data has been classified by country; e.g. data for the Russian Federation has been classified as being for a Very High HDI category country, while that for Kazakhstan as being for a High HDI category country.

2. Taiwan has been classified as a Very High HDI category country. Damage and death figures for Taiwan are given separately from China in the Louvain database, but since it is not recognised by the UN as a country separate from China, economic and population data have been estimated for Taiwan and subtracted from the China data.

3. The death and damage data for Very High HDI category countries are likely to be fairly reliable for all periods, but this reliability is thought to reduce rapidly with reducing HDI.

4. Allowing for inflation is not straightforward, because of the intrinsic difficulties in comparing the value of goods between different periods and between different HDI categories.

\section{Effect of removing the deaths and damage due to the Tangshan (1976) and Haïti (2010) earthquakes from Fig. 4}

Figure 9 shows the effect on Fig. 4 of removing the deaths and damage from these two earthquakes. The population and economic activity of both China (significant) and Haiti (insignificant) have however been retained in the normalizing calculations. The bar columns that are affected are for High HDI for the first period (Tangshan) and Low HDI for the second period (Haïti); the other bars are of course unchanged.

The lethality index for High HDI remains significantly reduced with Tangshan removed, and although the reduction is less dramatic than before, it seems safe to retain the conclusion that there is a real improvement in the ability of the high HDI countries to protect their citizens from earthquakes. However, the indices for both periods remain much greater than for the Very High HDI countries, and there is no sign as yet that the gap is closing.

The difference made by removing the Haiti earthquake is much more dramatic; it changes the lethality impact index from a staggering value of 25.1 to just 1.0 , and the economic impact index is reduced to around that for the Very High HDI countries. If we were confident that the disaster which struck Port-au-Prince in 2010 was a freak which could 'never happen again', we could safely ignore the 25.1 index value as irrelevant. Sadly, there is plenty of evidence that there are many Port-au-Prince's in seismic places around the world, which might (and probably will) suffer a similar disaster in the next 30 years; read the very readable but sobering book 'The million death quake' by a previous Mallet-Milne lecturer, Roger Musson (2012). 


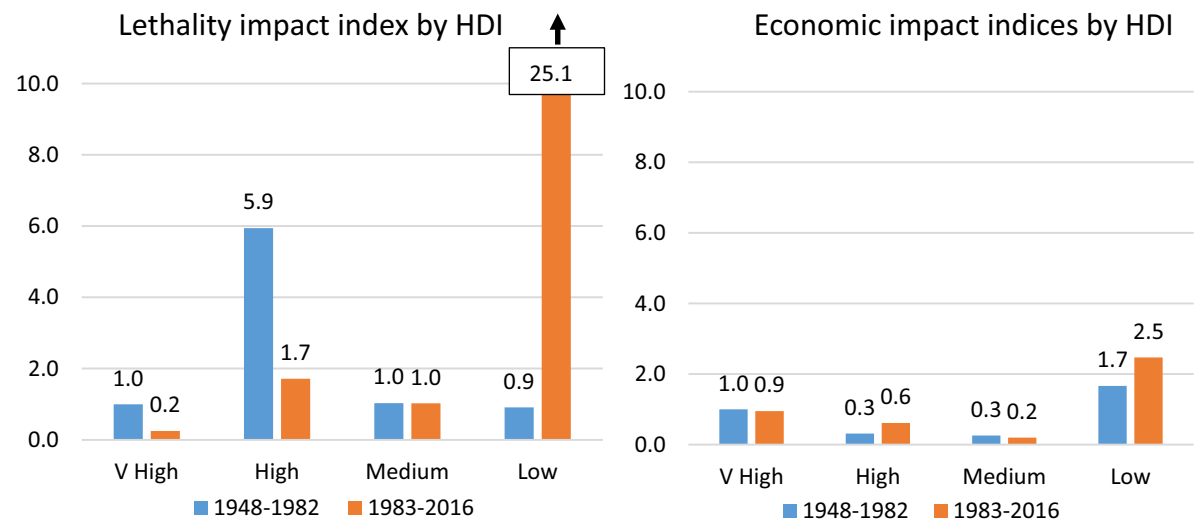

(a) 10

Lethality impact indices by HDI

8.0 after removing Tangshan \& Haiti

4.0

2.0

0.0

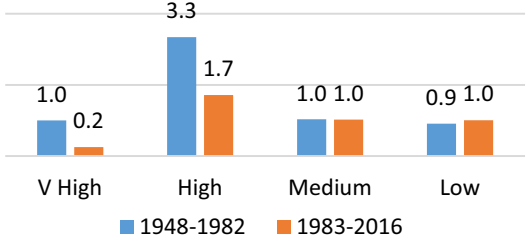

6.0

4.0

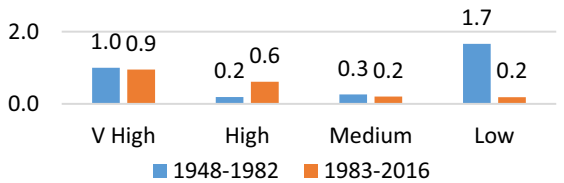

(b)

Fig. 9 Effect of removing data from Tangshan (1976) and Haïti (2010) on the impact indices. a Original data, including Tangshan and Haïti. b Revised data with Tangshan and Haïti removed

\section{Appendix 4: The global targets of the United Nation's Sendai Framework (UNIDSR 2015)}

(a) Substantially reduce global disaster mortality by 2030, aiming to lower the average per 100,000 global mortality rate in the decade 2020-2030 compared to the period 2005-2015;

(b) Substantially reduce the number of affected people globally by 2030 , aiming to lower the average global figure per 100,000 in the decade 2020-2030 compared to the period 2005-2015;

(c) Reduce direct disaster economic loss in relation to global gross domestic product (GDP) by 2030;

(d) Substantially reduce disaster damage to critical infrastructure and disruption of basic services, among them health and educational facilities, including through developing their resilience by 2030 ; 
(e) Substantially increase the number of countries with national and local disaster risk reduction strategies by 2020 ;

(f) Substantially enhance international cooperation to developing countries through adequate and sustainable support to complement their national actions for implementation of the present Framework by 2030;

(g) Substantially increase the availability of and access to multi-hazard early warning systems

\section{References}

Ahmed H (2017) Cambridge engineering: the first 150 years. Third Millennium Publishing, London

Almufti H, Willford M (2013) $\mathrm{REDi}^{\mathrm{TM}}$ rating system: resilience-based earthquake design initiative for the next generation of buildings, Arup. http://publications.arup.com

Ambraseys N, Bilham R (2011) Corruption kills. Nature 469:p153

Arup (1993) Earthquake hazard and risk in the UK. Department of the Environment, London, p 28

Berlin I (1953) The hedgehog and the fox: an essay on tolstoy's view of history. Weidenfeld \& Nicolson, London

Bevere L, Grollimund B (2012) Lessons from recent major earthquakes. Swiss Reinsurance Company Ltd, Zurich. http://media.swissre.com/documents)

Blockley D (2012) Engineering: a very short introduction. Oxford University Press, Oxford

Blockley D, Godfrey P (2017) Doing it differently: systems for rethinking infrastructure, 2nd edn. ICE Publishing, London

Bookstaber R (2017) The end of theory: financial crises, the failure of economics and the sweep of human interaction. Princeton University Press, Princeton

Booth E (2014) Earthquake design practice for buildings. ICE Publishing, London

Borchers J (2017) Out of the rubble: how can engineers overcome the problems between design and implementation in rural Nepal? Struct Eng, 95(11)

Bothara J, Sharpe R (2003) Seismic protection in developing countries: where are the gaps in our approach? In: 7th Pacific conference on earthquake engineering, Christchurch New Zealand. New Zealand Society for Earthquake Engineering, Wellington

Bruneau M, Chang S, Eguchi R, Lee G, O'Rourke T, Reinhorn A, Shinozuka M, Tierney K, Wallace W, von Winterfeldt DA (2003) Framework to quantitatively assess and enhance the seismic resilience of communities. Earthq Spectra 19(4):733-752

Bruyker De et al (1983) The 1980 earthquake in Southern Italy: rescue of trapped victims and mortality. Bull World Health Organ 612(6):1021-1025

Burton C, Silva V (2016) Assessing integrated earthquake risk in OpenQuake with an application to Mainland Portugal. Earthq Spectra 32(3):1383-1403

Calvi M, Sullivan T, Welch D (2014) A seismic performance classification framework to provide increased seismic resilience. In: Ansal A (ed) Perspectives on European earthquake engineering and seismology. Geotechnical, geological and earthquake engineering, vol 134. Springer, Cham, pp 361-400

Cannon T (2015) Disasters, climate change and the significance of 'culture'. In: Krüger F, Bankoff G, Cannon T, Orlowski B, Schipper ELF (eds) Cultures and disasters: understanding cultural framings in disaster risk reduction. Routledge, London

Canterbury Earthquakes Royal Commission (2012) Final report volume 2: the performance of Christchurch CBD buildings. http://canterbury.royalcommission.govt.nz

CEN (2004) EN 1998: design of structures in earthquake regions. European Centre for Standardization, Brussels

CERA (2014) Canterbury wellbeing index June 2014. Canterbury Earthquake Recovery Authority, Christchurch

Clarke D, Dercon S (2016) Dull disasters. Oxford University Press, Oxford

Comerio MC (2013) Housing recovery in Chile: a qualitative mid-program review. Department of Architecture University of California, Berkeley PEER report 2013/01

Da Silva J (2012) Shifting agendas: response to resilience: the role of the engineer in disaster risk reduction. The 2012 Brunel lecture

Despotaki V, Sousa L, Burton C (2017) Using resilience indicators in the prediction of earthquake recovery. Earthq Spectra. http://earthquakespectra.org/doi/abs/10.1193/071316EQS107M 
Dolce M, Di Pasquale G, Speranza E, Fumagalli F (2012) A multipurpose method for seismic vulnerability assessment of urban areas. In: Proceedings of the 15th world conference on earthquake engineering, Lisbon

DUDBC (1994) Nepal Building Code NBC 105: seismic design of buildings in Nepal. Department of Urban Development and Building Control, Kathmandu

EEFIT (2003) The Kocaeli, Turkey earthquake of 17 August 1999. Institution of Structural Engineers, London. Available from the EEFIT section of https://www.istructe.org

EEFIT (2013) Recovery two years after the 2011 Tōhoku earthquake and tsunami: a return mission report by EEFIT. Institution of Structural Engineers, London. Available from the EEFIT section of https://www. istructe.org

EERI (2016) M7.8 Gorkha, Nepal earthquake on April 25, 2015 and its aftershocks. Earthquake Engineering Research Institute, Oakland

Fox News (2017) Earthquake early-warning systems finally becoming a reality. http://www.foxnews.com/ tech/2017/02/06/earthquake-early-warning-systems-finally-becoming-reality.html. DOA 10/12/17

GeoHazards International (2001) Global earthquake safety initiative (GESI) pilot project. United Nations Centre for Regional Development, Nagoya

Ghosh S, Huyck CK, Greene M, Gill SP, Bevington J, Svekla W, DesRoches R, Eguchi RT (2011) Crowdsourcing for rapid damage assessment: the global earth observation catastrophe assessment network (GEO-CAN). Earthq Spectra 27:S179-S198

Gibb D (2014) Collectively we are stronger: the 10th Brunel lecture. Institution of Civil Engineers, London. https://www.ice.org.uk/eventarchive/10-brunel-international-lecture-cambridge

Green RA (2008) Unauthorised development and seismic hazard vulnerability: a study of squatters and engineers in Istanbul, Turkey. Disasters 32(3):358-376

Harford T (2015) Development needed? Just give cash. Financial Times Weekend Magazine, October 17/18

Hewitt K (2015) Framing disaster in the 'global village': cultures of rationality in risk, security and news. In: In: Krüger F, Bankoff G, Cannon T, Orlowski B, Schipper ELF (eds) Cultures and disasters: understanding cultural framings in disaster risk reduction. Routledge, London

Housner G (1989) The second mallet milne lecture: coping with natural disasters: the international decade for natural disaster reduction. The Society for Earthquake and Civil Engineering Dynamics (SECED), London

IFRC (2014) World disasters report: focus on culture and risk International Federation of Red Cross and Red Crescent Societies. http://www.ifrc.org/world-disasters-report-2014

Iwasaki N (2000) Role and functions of local communities in earthquake rescue, shelter administration and reconstruction. Int J Jpn Sociol 9(1):111-119

Johnson L, Mamula-Seadon L (2014) Transforming governance: how national policies and organizations for managing disaster recovery evolved following the 4 September 210 and 22 February 2011 Canterbury earthquakes. Earthq Spectra 30(1):577-605

Johnson L, Rabinovici S, Kang G, Mahin S (2016) California earthquake early warning system benefit study. CSSC Publication 16-04, California Seismic Safety Commission, Sacramento, California

Kahneman D (2011) Thinking fast, thinking slow. Penguin Books, London

Kelly D (2012) Quake safety cost must relate to risk. The Press, Christchurch, (15/06/12), Perspective

Kong Q, Allen R, Schreier L, Kwon Y-W (2016) MyShake: a smartphone seismic network for earthquake early warning and beyond. Sci Adv 2(2):e1501055

Krüger F, Bankoff G, Cannon T, Orlowski B, EL Schipper (eds) (2015) Cultures and disasters: understanding cultural framings in disaster risk reduction. Routledge, London

Langenbach R (2009) Don't tear it down! Preserving the Earthquake Resistant Vernacular Architecture of Kashmir. UNESCO, New Delhi

Los Angeles Times (2014) Garcetti wants L.A. buildings to be graded for earthquake safety. http://www. latimes.com. DOA 10/12/17

Lucas B, Hanson J, Claxton G (2014) Thinking like an engineer: implications for the education system. Royal Academy of Engineering, London

Makris N (2015) The dynamics of rocking isolation. SECED Newsl 26(2)

McNutt SR (1996) Seismic monitoring and eruption forecasting of volcanoes: a review of the state-of-the-art and case histories. In: Scarpa R, Tilling R (eds) Monitoring and mitigation of volcano hazards. Springer, Berlin

McVerry GH, Gerstenberger MC, Rhoades DA and Stirling MW (2012) Design spectra for the reconstruction of Christchurch. In: 15th world conference on earthquake engineering, Lisboa

Mouiller T, Krimgold F (2015) Building regulation for resilience: managing risks for safer cities. The World Bank, Washington D.C. https://www.gfdrr.org/sites/default/files/publication/BRR\%20report.pdf

Muir Wood R (2016) The cure for catastrophes. Oneworld Publications, London 
Musson RMW (2003) Fatalities in British earthquakes. Astron Geophys 44: 14-16. https://academic.oup. com/astrogeo/article/44/1/1.14/175896/Fatalities-in-British-earthquakes

Musson RMW (2012) The million death quake. Pagrave Macmillan, New York

Musson RMW (2013) The eleventh Mallet-Milne lecture: a history of British seismology. Bull Earthq Eng 11:715-861

NCE (2015) Letters page, 14th September 2015. New Civil Engineer

Noji EK, Armenian HK, Oganessian A (1993) Issues of rescue and medical care following the 1988 Armenian earthquake. Int J Epidemiol 22(6): 1070-1076. https://academic.oup.com/ije/article-abstract/ 22/6/1070/650167

Oliver-Smith A (2015) Conversations in catastrophe. In: Krüger F, Bankoff G, Cannon T, Orlowski B, Schipper ELF (eds) Cultures and disasters: understanding cultural framings in disaster risk reduction. Routledge, London

Olson RS, Olson RA (1987) Urban heavy rescue. Earthq Spectra 3(4):645-658

Park R, Paulay T (1975) Reinforced concrete structures. Wiley, New York

Paulay T (1993) The fourth Mallet-Milne lecture: simplicity and confidence in seismic design. SECED/John Wiley, Chichester

Penmellen Boret S, Shibayama A (2017) Learning from earthquake memorials: the case of the great East Japan disaster. Paper 1636, 16th world conference on earthquake engineering, Santiago de Chile

Platt S (2012) Reconstruction in Chile post 2010 earthquake; report funded by EPSRC. Cambridge Architectural Research, ImageCat and the Humanitarian Centre. http://www.carltd.com

Platt S (2017) Factors affecting the speed and quality of post disaster recovery and resilience. In: Rupakhety R, Olafsson S (eds) Earthquake engineering and structural dynamics in memory of Prof. Ragnar Sigbjörnsson: selected topics. Geotechnical, Geological and Earthquake Enginnering, Springer, Netherlands. http://www.carltd.com

Platt S, So E (2017) Speed or deliberation: a comparison of post-disaster recovery in Japan, Turkey and Chile. Disasters 41(4):696-727

Platt S, Hughes M and Brown D (2015) Measuring resilience and recovery. In: 7th international conference on seismology and earthquake engineering, Tehran. http://www.carltd.com

Poggi V, Durrheim R, Mavonga G, Weatherill G, Gee R, Pagani M, Nyblade A, Delvaux D (2017) Assessing seismic hazard of the East African rift: a pilot study from GEM and AfricaArray. Bull Earthq Eng 15(11):4499-4529

Press F (1984) An international decade for natural hazard reduction. In: Keynote address, 8th world conference on earthquake engineering, San Francisco

Rayasam R (2013) Do more women on the board mean better results? The New Yorker, 19-11-2013. http:// www.newyorker.com

Roberts D (2010) A lesson from Haiti: are search and rescue teams worth it? Philanthropy action, February. http://philanthropyaction.com/nc/a_lesson_from_haiti_are_search_and_rescue_teams_worth_it

Sanquini A, Thapaliya S, Wood M, Baiocchi M, Hilley G (2016) Encouraging earthquake-resistant construction: a randomized controlled trial in Nepal. Earthq Spectra 32(4):1975-1988

Schmidtlein M, Shafer J, Berry M, Cutter S (2011) Modeled earthquake losses and social vulnerability in Charleston, South Carolina. Appl Geogr 31(2011):269-281

Schumacher E (1973) Small is beautiful: a study of economics as if people mattered. Vintage, London

SEAONC (2011) SEAONC Rating system for the expected earthquake performance of buildings. In: SEAOC convention proceedings. Www.seaonc.org

Silva V, Crowley H, Pagani M, Monelli D, Pinho R (2014) Development of the OpenQuake engine, the global earthquake model's open-source software for seismic risk assessment. Nat Hazards 72(3):1409-1427

Silver N (2012) The signal and the noise: the art and science of prediction. The Penguin Press, London

Smolka A (2014) Extreme geohazards: risk management from a (re)insurance perspective. In: Ismail-Zadeh A et al (eds) Extreme natural hazards, disaster risks and societal implications. Cambridge University Press, Cambridge

Solnit R (2009) A paradise built in hell. Penguin Books, London

Spence R (2007) The eleventh Mallet-Milne lecture: saving lives in earthquakes: successes and failures since 1960. Bull Earthq Eng 5(2):

Stallings R (1990) Media discourse and the social construction of risk. Soc Probl 37(1):80-95

Stone H, D'Ayala D, Wilkinson S (2017) The use of emerging technology in post disaster reconnaissance missions. EEFIT, London

Toquica M, Burton C, Valcárcel JA (2017) Measuring social vulnerabilities to earthquakes in the Andean region. In: Proceedings of the 16th world conference on earthquake engineering, Santiago de Chile 
Twigg J, Mosel I (2017) Emergent groups and spontaneous volunteers in urban disaster response. Environment and Urbanization 29(2). http://journals.sagepub.com/doi/full/10.1177/0956247817721413

UNISDR (2015) The Sendai framework for disaster risk reduction, 2015-2030. United Nations Office for Disaster Risk Reduction, Geneva

Wikipedia (2017a) Kathmandu. https://en.wikipedia.org/wiki/Kathmandu. DOA 07-12-2017

Wikipedia (2017b) Nepal. https://en.wikipedia.org/wiki/Nepal. DOA 07-12-2017

Wikipedia (2017c) Demographics of New Zealand https://en.wikipedia.org/wiki/Demographics_of_New_ Zealand DOA 07-12-2017

Wikipedia (2017d) Christchurch earthquake. https://en.wikipedia.org/wiki/2011_Christchurch_earthquake DOA 07-12-2017

Wikipedia (2017e) McLean's mansion, Christchurch https://en.wikipedia.org/wiki/McLean\%27s_Mansion DOA 08-12-2017

Wikipedia (2017f) L'Aquila earthquake: prosecutions. https://en.wikipedia.org/wiki/2009_L\%27Aquila_ earthquake\#Prosecutions DOA 07-12-2017

Wikipedia (2017g) Critics say Japan ignored warnings of nuclear disaster. http://www.nytimes.com/2012/ 03/10/world/asia/critics-say-japan-ignored-warnings-of-nuclear-disaster.html. DOA 07-12-2017

Wikipedia (2017h) Smeatonian Society of Civil Engineers. https://en.wikipedia.org/wiki/Smeatonian_ Society_of_Civil_Engineers. DOA 08-12-2017

Worden CB, Wald DJ, Allen TI, Lin K, Garcia D, Cua G (2010) A revised ground-motion and intensity interpolation scheme for ShakeMap. Bull Seismol Soc Am 100(6):3083-3096 